ISSN: 0213-2079 - ISSN electrónico: 2386-3889

DOI: https://doi.org/10.14201/shhmo2020422329363

\title{
GRAN BRETAÑA Y LA CUESTIÓN CATALANA: LA NEGOCIACIÓN HISPANOBRITÁNICA DURANTE EL FINAL DE LA GUERRA DE SUCESIÓN ESPAÑOLA ${ }^{1}$
}

\section{Great Britain and the Catalan Question: the Hispano-British Negotiation during the End of the War of the Spanish Succession}

Manuel Alejandro CASTELLANO GARCÍA

Universitat Pompeu Fabra

manuelcastellanogarcia@gmail.com

Fecha de recepción: 02/01/2020

Fecha de aceptación: 18/09/2020

RESUMEN: Tras un largo periodo supeditado a la diplomacia francesa, la apertura de una negociación bilateral con Gran Bretaña permitió a Felipe V negociar por primera vez con voz propia. De entre los puntos a acordar, el conocido como «caso de los catalanes» acabó revistiendo mucha más importancia de la prevista al chocar la intención británica de conseguir el respeto a las leyes y constituciones catalanas contra la inamovible convicción de Felipe $\mathrm{V}$ en abolirlas. En el presente artículo analizamos la negociación abierta con el viaje de Lord Lexington a Madrid y culminada por el marqués de Monteleón en Londres: las instrucciones recibidas por los respectivos negociadores y sus informes unidos a los testimonios y correspondencia de muchos de los protagonistas implicados nos permiten reconstruir una compleja negociación que, aunque no cerró el debate

1. Este trabajo se enmarca en los proyectos España y Francia: Intereses dinásticos e intereses nacionales (1701-1733), PGC2018-097737-B-I00 y Grup d'estudi de les institucions i de les cultures polítiques (segles XVI-XXI) (2017 SGR 1041). Quisiera expresar mi agradecimiento a Joaquim Albareda por sus valiosas observaciones al texto inicial.

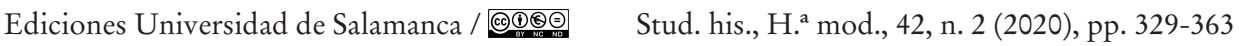


MANUEL ALEJANDRO CASTELLANO GARCÍA

GRAN BRETAÑA Y LA CUESTIÓN CATALANA: LA NEGOCIACIÓN HISPANOBRITÁNICA

DURANTE EL FINAL DE LA GUERRA DE SUCESIÓN ESPAÑOLA

del caso catalán, sí marcó de forma definitiva el futuro de las libertades y constituciones catalanas.

Palabras clave: Guerra de Sucesión española; caso de los catalanes; paz de Utrecht; Relaciones internacionales; Siglo XVIII.

ABSTRACT: After a long period of being dependent on French diplomacy, the opening of bilateral negotiation with Great Britain allowed Philip V to negotiate for the first time with his own voice. Among the points to be agreed, the one known as the «case of the Catalans» ended up being much more important than expected when the British intention to obtain respect for Catalan laws and constitutions collided against the immovable conviction of Philip V to abolish them. In this paper, we analyze the negotiation opened with Lord Lexington's mission to Madrid and culminated by the Marquis of Monteleón in London: the instructions received by the respective negotiators and their reports, together with the testimonies and correspondence of many of the protagonists involved allow us to reconstruct a complex negotiation that, although it did not close the debate on the Catalan case, definitively marked the future of Catalan freedoms and constitutions.

Keywords: War of the Spanish Succession; Catalan case; Peace of Utrecht; International relations; 18 th Century.

Entre las diversas cuestiones tratadas en las paces firmadas por la monarquía hispánica para concluir la guerra de Sucesión española, una de las más espinosas fue la resolución de la llamada «cuestión catalana».

A la tenaz resistencia de los territorios catalanes frente a las tropas borbónicas y sus intentos diplomáticos apoyados por el emperador Carlos VI -al menos temporalmente, ya que pese a su intransigencia inicial acabó aceptando la retirada de tropas de Cataluña y la neutralidad en Italia- se opuso la obcecación de Felipe V. Para el monarca era imprescindible eliminar las leyes catalanas y pese a los intentos de Luis XIV de moderar su postura se mantuvo firme convencido de que, como efectivamente sucedió, Gran Bretaña cedería por no arriesgar una paz que necesitaban, de la que obtendrían importantes réditos comerciales y en la que sus representantes políticos habían empeñado tanto.

Pese a que fue un tema que se prolongó más allá de la firma del tratado de Utrecht, volviendo a ser discutido en Rastatt y Baden y resonando incluso durante la negociación de la paz de Viena en 1725, sus líneas maestras se definieron entre

Ediciones Universidad de Salamanca / @®@@ Stud. his., H. ${ }^{a}$ mod., 42, n. 2 (2020), pp. 329-363 
MANUEL ALEJANDRO CASTELLANO GARCÍA

GRAN BRETAÑA Y LA CUESTIÓN CATALANA: LA NEGOCIACIÓN HISPANOBRITÁNICA DURANTE EL FINAL DE LA GUERRA DE SUCESIÓN ESPAÑOLA

1712 y 1713 en una negociación bilateral entre las cortes de Madrid y Londres que también decidió la paz rubricada en Utrecht entre ambas potencias.

Con el objetivo de profundizar en el conocimiento de la negociación de los asuntos catalanes buscaremos orientarnos hacia una visión más británica de los hechos. De esta forma, si bien apoyándonos en el solvente trabajo historiográfico ya realizado y la documentación existente en los archivos franceses y españoles, trabajaremos de forma más exhaustiva la rica documentación británica para llegar a un mejor entendimiento de sus actuaciones y estrategias al respecto. Igualmente, trataremos en paralelo las negociaciones sucedidas en Madrid y Londres tomando nota de la interrelación entre ambas y la influencia que lo que sucedía en una corte tenía en el proceso negociador que se llevaba a cabo en la otra. Todo ello sin olvidar la influencia ejercida por las cortes de París y -en menor medida- Viena, lo acontecido en Utrecht y los propios intentos catalanes para preservar sus intereses y conseguir que sus aliados cumpliesen los pactos suscritos con ellos.

\section{LA POSICIÓN DE PARTIDA DE FELIPE V}

El vuelco a la situación que permitió negociar exitosamente la paz se inició con los cambios gubernamentales promovidos por la reina Ana, que supusieron el retorno al poder de Robert Harley y la entrada en los principales cargos de responsabilidad política de tories en sustitución de los whigs, partidarios de continuar la guerra defendiendo el No peace without Spain. Ante el giro de la política británica el gobierno francés decidió sondear la disponibilidad del nuevo gabinete a un acuerdo de paz, comenzando los primeros contactos informales durante el verano de $1710 \mathrm{y}$ encauzándose la situación cuando las elecciones de octubre-noviembre del mismo año otorgaron una amplia mayoría tory en la Cámara de los Comunes. Además, las derrotas de Brihuega y Villaviciosa y la renovada iniciativa militar de las tropas felipistas acabaron de convencer a los británicos de que Carlos III jamás podría controlar la península (Coward, 2003: 480) facilitando la negociación bilateral entre Francia y Gran Bretaña. Esta, a espaldas de los respectivos aliados, concluyó con la firma en octubre de 1711 de los conocidos como Preliminares de Londres y la decisión de abrir un congreso de paz general en Utrecht.

Si algo define el periodo negociador que llevó al fin de la guerra de Sucesión española fue la dependencia de Felipe V respecto a Luis XIV. La propia Gran Bretaña exigió negociar los asuntos españoles a través de París y el rey francés, consciente de cuánto simplificaría el proceso y lo beneficioso que le sería, aceptó sin objeciones. Felipe $\mathrm{V}$ no tuvo más remedio que consentir y enviar a Versalles diversos poderes capacitando para negociar en su nombre. Además, tuvo que asumir que el congreso de Utrecht comenzaría sin sus plenipotenciarios al decidirse que no serían admitidos hasta que lo referente a la monarquía hispánica hubiera sido tratado.

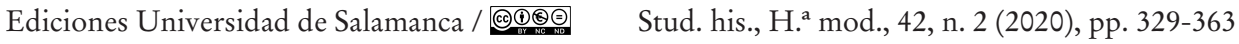


MANUEL ALEJANDRO CASTELLANO GARCÍA

GRAN BRETAÑA Y LA CUESTIÓN CATALANA: LA NEGOCIACIÓN HISPANOBRITÁNICA DURANTE EL FINAL DE LA GUERRA DE SUCESIÓN ESPAÑOLA

Para amortiguar estos golpes y no enrarecer más las relaciones con Madrid Luis XIV se ofreció a acoger en París a sus plenipotenciarios -el marqués de Monteleón, el duque de Osuna y el conde de Bergeyck- hasta que fuesen admitidos en Utrecht, prometiendo también mediar para que recibiesen los pasaportes necesarios lo antes posible (Guillamón y Muñoz, 2008: 181-182, carta CL). Esto último, además de no convenir al monarca francés era una mentira descarada: ya el 15 de diciembre Colbert de Torcy, secretario de Estado de Luis XIV, había asegurado a Henry St. John, Secretary of State for the Northern Department y futuro vizconde de Bolingbroke, que la ausencia de los plenipotenciarios de Felipe $\mathrm{V}$ no retrasaría las negociaciones y cuando llegasen a París el congreso llevaría largo tiempo empezado (Parke, 1798, Vol. II, 65-69).

Aceptada la propuesta, el 28 de diciembre de 1711 Felipe V envió sus instrucciones a sus plenipotenciarios. Era un extenso documento de cuarenta y cinco puntos en los que aun tratando aparentar total independencia queda clara su necesidad de asumir las decisiones tomadas en su nombre por Francia. Esto provocó que, como afirma Joaquim Albareda (2010: 321, 2013: 36), presentase aspiraciones territoriales maximalistas que resultaban contradictorias e incluso ingenuas. Respecto a Cataluña, su intención quedaba clara al expresar su punto 17:

de ninguna manera se den oydos a propósito de pacto que mire a que los catalanes conserven sus pretendidos fueros, pues sobre ser tan indignos de ellos (...) no es combeniencia ni decoro que la Paz General salga garante de tan vergonzante condición ni que por ella quedase la abitual propensión de los Catalanes a la revelión ${ }^{2}$.

Esta inflexibilidad no se vio disminuida en unas instrucciones posteriores que, aunque más acordes a las circunstancias en las que se desenvolvería la negociación (Albareda, 2013: 48-50), no presentaron cambios en cómo debía actuarse respecto a Cataluña.

Pero aunque la intención del monarca era clara aún debían darse las condiciones para que pudiese negociar, puesto que la diplomacia francesa seguía siendo la única interlocutora válida para los británicos. Hubo de esperar al éxito de la negociación realizada por Bolingbroke en Paris a mediados de agosto de $1712^{3}$ para que, junto con la decisión de enviar un representante a Madrid para ser testigo de la renuncia

2. Archivo Histórico Nacional (en adelante AHN), Estado, leg. 3376/2, n. ${ }^{\circ}$ 10, 28-XII1710. Un resumen detallado de ellas en Albareda Salvadó, J. (2013). Felipe y la negociación de los tratados de Utrecht: bajo los dictados del mejor abuelo del mundo. En 1713: la monarquía de España y los tratados de Utrecht. Cuadernos de Historia Moderna. Anejos, 12, 31-60.

3. El mismo Bolingbroke dio cuenta de su actuación en dos cartas a Strafford. Ver Parke, G. (ed.). (1798). Letters and correspondance, public and private, of the Right Honourable Henry St. John, lord viscount Bolingbroke, during the time he was secretary of state to Queen Anne, with state papers, explanatory notes and a translation of foreign letters, Vol. III, 1-23.

Ediciones Universidad de Salamanca / @®@@ Stud. his., H. ${ }^{a}$ mod., 42, n. 2 (2020), pp. 329-363 
MANUEL ALEJANDRO CASTELLANO GARCÍA

GRAN BRETAÑA Y LA CUESTIÓN CATALANA: LA NEGOCIACIÓN HISPANOBRITÁNICA DURANTE EL FINAL DE LA GUERRA DE SUCESIÓN ESPAÑOLA

de Felipe $\mathrm{V}$ a sus derechos sobre la corona francesa y discutir los puntos restantes relativos a las negociaciones hispano-británicas, se consintiese la entrada en Londres de un enviado de Felipe V.

Fueron por tanto las llegadas de Robert Sutton, barón de Lexington, a Madrid el 18 de octubre de 1712 y del marqués de Monteleón a Londres el 16 de diciembre del mismo año las que permitieron por primera vez a Felipe $\mathrm{V}$ negociar con voz propia y durante las que se decidió en gran medida el destino de los catalanes.

\section{LAS PRIMERAS NEGOCIACIONES EN MADRID}

Así pues, la presencia de Lord Lexington en Madrid marcó el inicio de la negociación hispano-británica. No parecía el candidato más adecuado para la misión, uniéndose a su mala salud la falta de dominio de la lengua castellana y sus escasos conocimientos sobre la corte de Felipe V (Storrs, 2013: 82-83). Además, su anterior encargo diplomático en Viena le hacía sospechoso de simpatías austracistas a ojos de Felipe V, la reina y varios de sus ministros, que acabaron acusándole de tener gran inclinación por la Casa de Austria y pelear con mucho ahínco por sus intereses ${ }^{4}$. Pero como desde la muerte de Alexander Stanhope carecían de diplomáticos versados en la monarquía hispánica, se le eligió a sabiendas de que al menos aseguraba la presencia de un tory fiel a los dictados del gobierno.

En sus instrucciones se le encomendó defender la concesión de un perdón general a los súbditos que apoyaron a la casa de Austria, debiendo hacer especial mención a los catalanes y solicitando el mantenimiento de sus dignidades, estados, personas y privilegios 5 .

Por supuesto no era la única cuestión a tratar, debiendo también definir las cesiones de Menorca y Gibraltar, logrando en este último emplazamiento un terreno adyacente igual a la distancia cubierta por dos disparos de cañón. Igualmente se le encargó confirmar la obtención del asiento de negros y las mismas ventajas comerciales que al socio comercial más favorecido; la deducción del $15 \%$ en todos los bienes al comercio británico; instar a renovar los acuerdos de amistad y comercio quedando las regulaciones comerciales, excepto lo ajustado en el nuevo tratado, en el mismo pie que durante el reinado de Carlos II; salvaguardar los intereses comerciales británicos y garantizar el respeto a los privilegios de los cónsules británicos en los puertos españoles ${ }^{6}$.

Sin embargo toda la negociación se condicionaba a la previa renuncia de Felipe $\mathrm{V}$ al trono francés, ya que solo tras ella asumiría su condición de embajador

4. National Archives (en adelante N. A), SP 94/80 s/n, Lexington a Dartmouth, 17-IV-1713.

5. N. A. SP 104/133, f. 19.

6. N. A. SP $105 / 269$, s/n y N. A. SP 104/133, ff. 14-22.

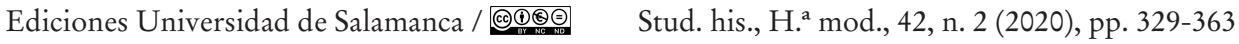


MANUEL ALEJANDRO CASTELLANO GARCÍA

GRAN BRETAÑA Y LA CUESTIÓN CATALANA: LA NEGOCIACIÓN HISPANOBRITÁNICA DURANTE EL FINAL DE LA GUERRA DE SUCESIÓN ESPAÑOLA

extraordinario. De hecho, el propio Luis XIV comunicó su embajador en Madrid, el marqués de Bonnac, que Lexington acudía para ser testigo de ella (Courcy, 1889: 186-187). Esto nos refuerza en la opinión ya expresada por Christopher Storrs (2013: 79) de que, pese a la importancia de la negociación, el motivo principal del viaje era comprobar que transcurriese según lo acordado y fuese debidamente confirmada y registrada en las Cortes.

Por otro lado sus instrucciones buscaban únicamente confirmar y concretar los puntos pactados con los franceses, careciendo de auténtica capacidad negociadora y obligando a remitir toda objeción a Londres. Esto acabó provocando la protesta de sus interlocutores, convencidos de que las demandas eran excesivas y Francia había sacrificado intereses españoles para obtener mejores condiciones para ellos ${ }^{7}$.

Aún existió otro punto polémico respecto a sus instrucciones ya que, aunque le capacitaban para reconocer oficialmente a Felipe V como legítimo monarca, solo le facultaban a hacerlo una vez hubiese renunciado al trono francés, aceptado la sucesión protestante al trono británico y expresado su decisión de cumplir los compromisos asumidos por Luis XIV en su nombre. Junto a la gran desconfianza que mostraban, provocarían que Lexington no solicitase audiencia real al llegar a Madrid e incluso pretendiese asistir a la ceremonia de renuncia sin reconocer la legitimidad de Felipe V. Teniendo en cuenta que el monarca ya había tomado su llegada como prueba del escaso valor que la corte británica daba a su palabra (Baudrillart, 1890: 508), la situación amenazaba con originar un conflicto diplomático. Torcy, que conoció a través del poeta y diplomático británico Matthew Prior el contenido de las instrucciones, informó a Londres de que Felipe V se sentiría profundamente insultado, lo que complicaría el éxito de la negociación ${ }^{8}$.

Tras achacarlo a un error al plasmar las intenciones de la reina, Bolingbroke aseguró que si bien Lexington no asumiría la dignidad de embajador hasta aceptarse dichas condiciones no habría impedimentos en que reconociese a Felipe $\mathrm{V}$ como legítimo rey de España (Parke, 1798, Vol. III, 45-46). En efecto, una nueva carta instó a Lexington a que tras llegar a Madrid solicitase inmediatamente audiencia privada con los reyes, reconociéndoles dicha calidad. Eso sí, no presentaría su credencial diplomática hasta realizarse la renuncia al trono francés y recibir garantías escritas de que accederían a lo acordado por Luis XIV en su nombre9. Para acabar de tranquilizar a los franceses Bolingbroke informó a Torcy de que Lexington había estado presente en la redacción de sus nuevas instrucciones y sido oralmente instruido, por

7. British Library (en adelante B. L.), Add. MS 6543A, f. 46, Lexington a Bolingbroke, 14-XI-1712.

8. Archive Diplomatique des Affaires Étrangères (en adelante AMAE), CP. Anglaterre. 242, ff. 61-62, Torcy a Harley, 11-IX-1712.

9. N. A. SP 104/133, ff. 31-33, Dartmouth a Lexington, 10/21-IX-1712.

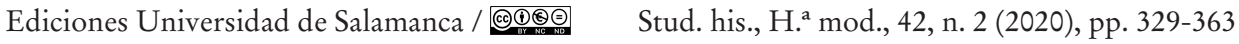


MANUEL ALEJANDRO CASTELLANO GARCÍA

GRAN BRETAÑA Y LA CUESTIÓN CATALANA: LA NEGOCIACIÓN HISPANOBRITÁNICA DURANTE EL FINAL DE LA GUERRA DE SUCESIÓN ESPAÑOLA

lo que no existía peligro de que por una mala interpretación desairase a Felipe V (Parke, 1798, Vol. III, 62-64).

Tras llegar a Madrid y mantener la audiencia real Lexington comenzó a negociar con los designados para ello, el marqués de Grimaldo y el marqués de Bedmar, si bien dejando constancia de sus dificultades idiomáticas y como estas interferían en el proceso negociador:

I treat with all the disavantage ever man did for I am not master of Spanish and none of the ministers understands anything else except the Marquis of Bedmar, nor will they give me copies of their papers in any other language ${ }^{10}$.

Tal vez esto explica que Grimaldo le informase de que aunque debía dirigirse a él si quería presentar alguna propuesta secreta, Bedmar sería su principal interlocutor. Efectivamente, en los dos días siguientes a su llegada mantuvo sendas reuniones con Bedmar que supusieron una primera toma de contacto y en las que presentó las demandas británicas.

Llama la atención lo escueto de los informes de Lexington sobre estos dos primeros encuentros. Se limitó a comentar al conde de Dartmouth, Secretary of State for the Southern Department, que el primer día entregó los once puntos de que constaban sus instrucciones y, tras debatir brevemente las cuestiones clave, Bedmar le solicitó unos días de plazo para consultar sus demandas con el rey, por lo que se mantenía a la espera de respuesta ${ }^{11}$. A Harley solo le expresó que le suponía enterado de sus actuaciones a través de su envío a Dartmouth añadiendo que había sabido que Felipe V, aunque indignado con los franceses por querer cargarle todos los sacrificios de la paz, mantendría las promesas hechas en su nombre y de haber alguna diferencia sería fácilmente negociable ${ }^{12}$.

Dada su parquedad, para conocer en profundidad lo sucedido respecto a la cuestión catalana en estas primeras reuniones debemos recurrir a Bedmar, quien expuso que no era un tema que debiera tratarse en este acuerdo y menos manteniéndose dichos súbditos en abierta rebeldía. Por ello propuso remitirla a los acuerdos de paz general, algo que Lexington pareció aceptar sin problemas solicitando únicamente la seguridad de que llegado el momento Felipe $\mathrm{V}$ «tendría piedad de esos desdichados» ${ }^{13}$. El 25 de octubre Bedmar le entregó la respuesta del rey, que

10. Carta de Lexington, 31-X-1712, citado en Horn, D. B. (1961). The British diplomatic service, 1698-1789. Oxford: Clarendon Press, 38.

11. B. L. Add. MS 46543 A, ff. 101-102, Lexington a Dartmouth, 21-X-1712. Copias en N.A. SP $94 / 79$ s/n y N.A. SP $105 / 269$, s/n.

12. N. A. SP 105/269, s/n, Lexington a Harley, 23-X-1712.

13. Archivo General de Simancas (en adelante AGS), Estado, leg. 6820, Papel del marqués de Bedmar de 21 de octubre de 1712 de la conferencia que tuvo con Lexington.

Ediciones Universidad de Salamanca / @®@@ Stud. his., H. ${ }^{a}$ mod., 42, n. 2 (2020), pp. 329-363 
MANUEL ALEJANDRO CASTELLANO GARCÍA

GRAN BRETAÑA Y LA CUESTIÓN CATALANA: LA NEGOCIACIÓN HISPANOBRITÁNICA DURANTE EL FINAL DE LA GUERRA DE SUCESIÓN ESPAÑOLA

no fue otra que emplazar la solicitada amnistía a un apartado de la negociación de paz general que también garantizase la restitución de todo bien, honor o dignidad perdida por aquellos súbditos que hubiesen apoyado la causa borbónica ${ }^{14}$.

Cuando tres días después recibió la respuesta oficial a las peticiones británicas el informe redactado por Lexington a Londres zanjaba la cuestión catalana con una única frase: "The $11 t^{15}$ agreed to, for I think what they desire is but justice» ${ }^{16}$. Esta rápida aceptación se suma al hecho de que, pese a que sus instrucciones especificaban solicitar el mantenimiento de dignidades, estados, personas y privilegios, únicamente demandó una amnistía general. Con este apunte no pretendemos alimentar la teoría de la existencia de una suerte de conspiración entre Luis XIV y Lexington para, con beneplácito británico, dejar a los catalanes en manos de Felipe V (Guerrero, 2008: 437-438) pero es importante reseñarlo porque permite constatar que además de no ser un negociador avezado -también cometió varios errores al negociar lo plasmado en sus instrucciones ${ }^{17}$, había asumido como justa la postura de Felipe $\mathrm{V}$ respecto a Cataluña.

De hecho, para él su misión había concluido con éxito, quedando solo a la espera de retomar algún asunto que no pudiera ser acordado con Monteleón en Londres ${ }^{18}$. Si más adelante volvió a negociar el respeto a las leyes y privilegios catalanes, y con una insistencia que llegó a ser elogiada por Bonnac ${ }^{19}$, se debió únicamente a que en la respuesta a su informe Dartmouth le exhortó a poner todo su empeño en conseguir un buen trato para los catalanes:

An Amnisty to the Catalans is the affair which above all others in Her Majesty opinion requires the greatest dispatch for besides this is an act of humanity which everybody to the utmost of his power ought to promote ${ }^{20}$.

Por tanto no fue hasta la llegada de la respuesta de Londres cuando se retomó en Madrid la cuestión catalana, ocupándose Lexington hasta entonces de temas relativos a la renuncia de Felipe $\mathrm{V}$ al trono francés y tratando, sin fortuna, de obtener avances en cuestiones polémicas como la exención del 15\% a los productos británicos.

14. N. A. SP 105/269, s/n, Respuesta de la Corte de España a las propuestas de Milord Lexington, 25-X-1712.

15. El perdón general a los súbditos que hubiesen apoyado a la casa de Austria y en especial a los catalanes era el undécimo punto del listado de peticiones.

16. N. A. SP 105/269, s/n, Lexington a Dartmouth, 28-X-1712.

17. Por ejemplo debía solicitar un territorio adyacente a Gibraltar de dos disparos de cañón de longitud, pero en su primer encuentro con Bedmar mencionó únicamente «una cierta extensión de tierra», para más adelante demandar la distancia correspondiente a un disparo.

18. N. A. SP 105/269, s/n, Lexington a Dartmouth, 28-X-1712.

19. Ver, por ejemplo, AMAE CP. Espagne, $220 \mathrm{ff} .73 \mathrm{v}-74$ Bonnac a Versalles, 20-I-1713.

20. N. A. SP 104/133, s/n, Dartmouth a Lexington, 7-XI-1712. 
MANUEL ALEJANDRO CASTELLANO GARCÍA

GRAN BRETAÑA Y LA CUESTIÓN CATALANA: LA NEGOCIACIÓN HISPANOBRITÁNICA

DURANTE EL FINAL DE LA GUERRA DE SUCESIÓN ESPAÑOLA

La carta que marcó las nuevas pautas negociadoras a Lexington fue escrita el 7 de noviembre, pero sufrió la extrema lentitud del correo. Esta llegó a tal punto que Lexington, creyendo que sus misivas podían haberse extraviado, escribió a Dartmouth a principios de diciembre preocupado por la ausencia de correspondencia adjuntando un listado de las cartas que había remitido y un duplicado de la carta de 28 de octubre en la que, como hemos mencionado, daba cuentas de su negociación ${ }^{21}$. Todo ello obligó a retrasar sus actuaciones hasta mediados de diciembre, superponiéndose sus gestiones sobre la cuestión catalana con las que, en Londres, llevaban a cabo los ministros británicos con el marqués de Monteleón.

\section{UNA NEGOCIACIÓN A DOS BANDAS: EL EJE LONDRES-MADRID}

\subsection{El inicio de la negociación de Monteleón}

Pese a que Lexington había dado por concluida la cuestión catalana, desde Londres no solo le ordenaron redoblar sus esfuerzos sino que buscaron reconducir la situación aprovechando la llegada de Monteleón para tratar este tema de manera coordinada en ambas cortes.

Si bien Monteleón ya solicitó el pasaporte para viajar a Londres a principios de octubre ${ }^{22}$ las autoridades británicas demoraron su envío hasta que se materializó la renuncia de Felipe $\mathrm{V}$ al trono francés. Así, pese a sus protestas por el perjuicio de que se tratasen los asuntos españoles sin poder defender sus intereses (Albareda, 2013: 50-51), no pudo partir hasta principios de diciembre, llegando a Londres el 16 de dicho mes.

Los británicos, que elogiaron su disposición a no alargar la negociación ${ }^{23}$, le definieron como hábil y honesto aunque indiscreto ${ }^{24} \mathrm{y}$ menos pro-francés de lo esperado (Parke, 1798: Vol. III, 363-364), ya que pese a que tendía a aceptar los consejos que recibía de Torcy (Bély, 1990: 424) se aplicó en demostrar la independencia de Felipe $\mathrm{V}$ respecto a Luis XIV ${ }^{25}$. Monteleón, además, no estuvo solo en Londres: recibió orden de ayudarle el abbé Gaultier ${ }^{26}$, un agente de Torcy que ya había sido responsable de iniciar los contactos preliminares entre franceses y británicos (Castellano, 2016: 258-268), y que se esmeró tanto en cumplir su cometido que Monteleón lo

21. N. A. SP 94/79, s/n, Lexington a Dartmouth, 5-XII-1712.

22. N. A. SP 94/79, s/n, carta de Monteleón, 3-X-1712.

23. B. L. Add. MS. 49971, f. 44v, St. John a Torcy, 13/24-XII-1712.

24. AMAE, CP. Anglaterre. 243, f. 148v, Aumont a Torcy, 2-II-1713.

25. B. L. Add. MS 46546, f. 5, Erasmus Lewis a Lexington, 27-XII-1712.

26. AMAE, CP. Anglaterre. 242, f. 241v, Torcy a Gaultier, 28-XII-1712.

Ediciones Universidad de Salamanca / @@@ Stud. his., H. ${ }^{a}$ mod., 42, n. 2 (2020), pp. 329-363 
MANUEL ALEJANDRO CASTELLANO GARCÍA

GRAN BRETAÑA Y LA CUESTIÓN CATALANA: LA NEGOCIACIÓN HISPANOBRITÁNICA DURANTE EL FINAL DE LA GUERRA DE SUCESIÓN ESPAÑOLA

calificó de «instrumento del que se ha valido la providencia para la obra de la paz» solicitando para él un beneficio de 4.000 ducados por sus servicios ${ }^{27}$.

Pese al interés de ambas partes en una negociación rápida esta tardó varios días en iniciarse, posiblemente porque Bolingbroke esperaba la llegada de cartas explicando ciertos aspectos comerciales tratados en $\mathrm{Madrid}^{28}$. Sin embargo las entrevistas previas convencieron a Monteleón de las buenas intenciones británicas, y durante los primeros encuentros todo fluyó con tanta facilidad que también los británicos creyeron que la negociación se resolvería rápidamente (Parke, 1798: Vol. III, 276).

Si bien trataron todos los temas que tenía Monteleón en su agenda, se prestó especial atención a la cuestión catalana. Dartmouth insistió en la importancia que la reina concedía a este punto y expuso la sorpresa que había provocado saber que Felipe $\mathrm{V}$ no pensaba mantener los privilegios catalanes ya que, siendo obvio que no pasaría por las armas a toda una provincia, la amnistía no tenía sentido si no garantizaba sus derechos y privilegios ${ }^{29}$. Pero Monteleón confirmó que dado que los catalanes se habían mostrado indignos de conservarlos y de hacerlo podrían molestar la tranquilidad de España e incluso de Inglaterra ${ }^{30}$, Felipe V estimaba suficiente una amnistía general asegurando vidas, honores y bienes particulares siempre que fuese recíproca para los fieles al bando borbónico ${ }^{31}$.

Pese a los problemas que estaba causando la cuestión catalana Monteleón pensaba, de forma optimista, que se pondría fin a la guerra en los términos generales propuestos por los británicos, más aún tras saber que Holanda concurría a la paz a cambio de una barrera segura y el emperador aceptaba el armisticio y la amnistía en Italia, la cesión de Sicilia al duque de Saboya y la evacuación de tropas de Cataluña.

Convencido también de la simpatía británica procuró negociar más rápidamente y que la corte española redujese las formalidades aceptando sus ofertas sin el trámite de que fuesen firmadas por la reina ${ }^{32}$. Esa buena predisposición no evitó que días después, mientas negociaba la respuesta a la propuesta sobre el tratado de evacuación de Cataluña y neutralidad en Italia presentado por el conde de Sinzendorf, enviado imperial en Utrecht, insistiese en que su punto noveno, que solicitaba el mantenimiento de los privilegios catalanes, únicamente acordase de forma general el perdón de los catalanes ${ }^{33}$.

27. AMAE, CP Anglaterre. 244, f. 201-202, Monteleón a la corte, 18-IV-1713. Dicho beneficio fue otorgado sobre las rentas del arzobispado de Toledo.

28. AMAE, CP. Anglaterre. 240, f. 285, St. John a Torcy de 19-XII-1712.

29. N. A. SP 105/270, ff. 37-38, extracto de la carta de Dartmouth a Monteleón, 14-I-1713.

30. AMAE, CP Anglaterre. 243, f. 109, Respuesta de Monteleón al conde de Dartmouth, $25-\mathrm{I}-1713$.

31. AMAE, CP. Anglaterre. 243, f. 97, Monteleón a Grimaldo, 19-I-1713.

32. AMAE, CP. Anglaterre. 243, ff. 88-89, Monteleón a Torcy, 19-I-1713.

33. AMAE, CP. Anglaterre. 243, f. 107, Monteleón, 22-I/2-II-1713.

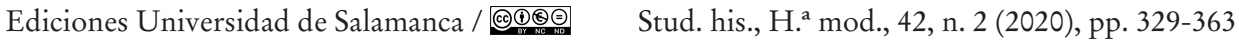


MANUEL ALEJANDRO CASTELLANO GARCÍA

GRAN BRETAÑA Y LA CUESTIÓN CATALANA: LA NEGOCIACIÓN HISPANOBRITÁNICA DURANTE EL FINAL DE LA GUERRA DE SUCESIÓN ESPAÑOLA

Pero en líneas generales la negociación avanzaba a buen ritmo, y cuando el cinco de febrero recibió las respuestas de la reina se encontró con que muchos puntos a tratar habían quedado total o prácticamente allanados.

Sin embargo la cuestión catalana no era uno de ellos. Los británicos apuntaron que pese a ver razonable añadir un artículo en el tratado de paz garantizando a los súbditos de Felipe $\mathrm{V}$ en zonas austracistas el restablecimiento de bienes y honores, la libre disposición de bienes y la libertad de seguir a su servicio fuera de esos territorios o volviendo a España, la reina se veía obligada a intervenir en favor de los catalanes por estar empeñado su honor. Recordaron que ya la amnistía general propuesta por Francia en abril de 1712 implicaba la conservación de privilegios, añadiendo que tras retirar Gran Bretaña sus tropas de Cataluña y preparar la salida de las tropas imperiales esperaban que en agradecimiento se satisficiese su petición de dejar a los catalanes en el mismo estado en que iniciaron la guerra ${ }^{34}$.

No era el único lugar donde la cuestión catalana creaba conflictos, ya que tras la respuesta de Felipe $\mathrm{V}$ al proyecto de tratado de evacuación de Cataluña y la contrapropuesta de Carlos VI era precisamente el artículo 9 el que evitaba el acuerdo total al pretender el emperador que asegurase para Cataluña la conservación de sus leyes y constituciones. Pero Felipe V se mantuvo firme en ofrecer $-\mathrm{y}$ remarcando que lo hacía a petición de Su Majestad Británica- únicamente amnistía y perdón, dejando todos los restantes aspectos emplazados a las conversaciones de paz general ${ }^{35}$.

Así, aunque el caso catalán parecía haber llegado a un punto muerto, en líneas generales Monteleón era tremendamente optimista y solo lamentaba su tardía llegada a Gran Bretaña ya que, en su opinión, de haber podido ir antes un ministro de Felipe $\mathrm{V}$ la situación se habría resuelto antes y en mejores condiciones ${ }^{36}$.

\subsection{El fracaso de Lexington}

Mientras Monteleón iniciaba su negociación Lexington recibió la esperada respuesta de Londres sobre su actuación. Esta insistía en la necesidad de lograr la completa amnistía para los catalanes, recomendándole hacer ver a Felipe V que tal acto de humanidad le beneficiaría al calmar a esos súbditos y, haciéndoles volver más firmemente a la obediencia real, debilitar la causa del emperador en la península ${ }^{37}$.

34. AMAE, CP. Anglaterre. 243, ff. 110-117. Proposición hecha por el marqués de Monteleón y respuestas de la reina de Gran Bretaña, 25-I/5-II-1713.

35. B. L. Add. MS 46549, ff. 101-107, Respuesta de Felipe V a la propuesta de evacuación de Cataluña, 9-II-1713. Bonnac envió una copia a Versalles que puede consultarse en AMAE, CP. Espagne. 220, ff. 98-103.

36. AMAE, CP. Anglaterre. 243, ff. 92v-97, Monteleón a Grimaldo, 19-I-1713.

37. B. L. Add. MS 46545, f. 68, Dartmouth a Lexington, 7/18-XI-1712.

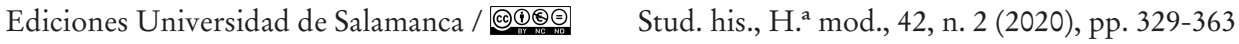


MANUEL ALEJANDRO CASTELLANO GARCÍA

GRAN BRETAÑA Y LA CUESTIÓN CATALANA: LA NEGOCIACIÓN HISPANOBRITÁNICA DURANTE EL FINAL DE LA GUERRA DE SUCESIÓN ESPAÑOLA

Por eso el 15 de diciembre presentó un nuevo documento solicitando la amnistía completa por estar empeñada la palabra y el honor de la reina y ofreciendo su reciprocidad a todos los súbditos de Felipe V para hacerla más atractiva. Pero la respuesta volvió a dejar clara la intransigencia real en esta cuestión: tras enumerar las razones por las que podría negarse a otorgarla, Felipe $\mathrm{V}$ garantizó el perdón a los súbditos que volviesen a la obediencia real dentro del plazo que establecería para ello, pero sin incluir la más mínima alusión a los privilegios y leyes catalanas ${ }^{38}$.

El bloqueo en esta cuestión, pero también en otras como el empeño del monarca en lograr un principado en Limburgo para la camarera real de la reina, princesa de los Ursinos ${ }^{39}$, y lo relativo a los acuerdos comerciales parecieron llevar la negociación a un punto muerto. Esto hizo cundir la impaciencia en Londres, que presionó a Lexington ante la falta de avances:

in short, My Lord, there is no more time to be lost (...) it is high time to conclude. The Parliament stands now prorogued to the third of February, the Queen must speak of her interest as determined with France and Spain; should the negotiation afterwards appear to be open, nobody can answer the consequences ${ }^{40}$.

Pero la cuestión catalana no ensombrecía únicamente la negociación hispanobritánica sino que también se había convertido en uno de los puntos más problemáticos para finalizar el acuerdo de evacuación de Cataluña. Que Carlos VI considerase clave que las leyes, constituciones y libertades catalanas fuesen respetadas hizo que también los portugueses preguntasen a Lexington cómo actuar al respecto ${ }^{41}$. Ante esta petición, unida a la realizada por el conde de Starhemberg ${ }^{42}$ y las propias órdenes recibidas desde Londres, Lexington solicitó y obtuvo dos nuevas audiencias reales en búsqueda de las deseadas garantías de plena conservación de los privilegios catalanes.

Si ya en la primera audiencia recibió una nueva negativa al exponer las razones por la que el monarca debería reconsiderar su decisión, mucho más llamativo fue lo sucedido en la segunda. Lexington quedó profundamente sorprendido cuando

38. N.A. SP 94/79, s/n, Respuesta al memorial presentado por Lord Lexington. Existe una traducción al inglés en N. A. SP 104/133, s/n.

39. Ver Albareda, J. (2018). Une principauté pour la princesse des Ursins: difficultés et échec. En G. Hanotin y D. Pico (dirs.), Le lion et les lys: Espagne et France au temps de Philippe V. Burdeos: Presses Universitaires de Bourdeux, 189-206 y Horowski, L. (2018). Subjects into sovereigns: The outsiders' pursuit of sovereignity and the war of the Spanish sucession. En M. Pohlig y M. Schaich (dirs.), The war of the Spanish Succession: new perspectives, Oxford: Oxford University Press. 122-127.

40. Parke, G. (ed.). (1798). Letters and correspondence... op. cit., Vol. III, 292, Bolingbroke a Lexington, 7-I-1713.

41. N. A. SP 105/270, f. 45, extracto de la carta del conde de Assumar a Lexington, 24-I-1713.

42. Lexington menciona la petición de Starhemberg en su carta a Dartmouth de 6-II-1713 (En N. A. SP 94/80, s/n). 
MANUEL ALEJANDRO CASTELLANO GARCÍA

GRAN BRETAÑA Y LA CUESTIÓN CATALANA: LA NEGOCIACIÓN HISPANOBRITÁNICA DURANTE EL FINAL DE LA GUERRA DE SUCESIÓN ESPAÑOLA

al surgir el tema catalán los reyes comenzaron a gritar acaloradamente, interrumpiéndose mutuamente y expresando que jamás acordarían mantener los privilegios "para esos canallas, esos bribones», ya que de hacerlo Felipe V se vería imposibilitado de reinar en su propio reino. Una afirmación tan tajante y especialmente la forma en que había sido expresada le hizo comprender que no le quedaba sino retirarse, aunque antes solicitó comentar la cuestión con Bedmar.

Tampoco en esa entrevista, en la que también debía discutir ciertos puntos sobre el cese de armas en Cataluña y la salida de las tropas imperiales, obtuvo avances. Más aún, cuando incidió sobre el peligro de retardar la paz y las ventajas que obtendría Felipe V si cambiaba de opinión, Bedmar se limitó a responder que aunque entendía que como ministro británico hiciese todas las gestiones que creyera convenientes no esperase más respuesta que la que ya había obtenido ${ }^{43}$.

Lexington quedó convencido de que no había esperanzas para las leyes y libertades catalanas y así lo hizo saber al conde de Assumar, embajador portugués en la corte imperial en Barcelona, en una misiva donde nuevamente mostraba que lo consideraba una postura lógica. Queda claro al ver como expresó al portugués que realizaría un último intento si él le hacía llegar una propuesta que supusiera un término medio aceptable entre «unos privilegios tan excesivos y una justa libertad» ${ }^{44}$.

En un tono similar explicó a Dartmouth que Felipe V había declarado que era suficiente concesión mantener los bienes y vidas de quienes se acogiesen a la amnistía y que antes de ceder privilegio alguno a los catalanes se arriesgaría a una nueva campaña militar. Añadió que en Madrid todos eran tan conscientes de la firmeza de su decisión que Bergeyck se había negado a comentar siquiera al rey los argumentos que le había presentado en otra de sus entrevistas. Por ello, y en vista de que su falta de poderes le impedía ofrecer contraprestaciones, dejaba el asunto en manos de los negociadores que en Londres trataban con Monteleón ${ }^{45}$.

Lo cierto es que Felipe V era consciente de que Gran Bretaña deseaba la paz y no haría un escollo insalvable de lo que, en definitiva, no dejaba de ser un asunto interno. Esto le convencía de poder mantener su posición de fuerza y así se lo había hecho saber a Lexington: «the King told me these words: Monsieur, nous savons que la paix vous est aussy necesaire qu' à nous, et vous ne voulez pas la rompre pour une bagatelle» ${ }^{46}$.

A pesar de ello desde Londres comunicaron su sorpresa por la cerrazón de Felipe $\mathrm{V}$ en un punto en el que la reina se sentía personalmente obligada y le ordenaron seguir insistiendo. Debía hacer ver al monarca que incluir los privilegios catalanes

43. N. A. SP 105/270, ff. 50-51, Lexington a Shrewsbury, 30-I-1713.

44. N. A. SP 105/270, f. 53, Lexington al conde de Assumar, 3-II-1713.

45. N. A. SP 94/80, s/n, Lexington a Dartmouth, 6-II-1713.

46. N. A. SP 105/270, f. 61, Lexington a Dartmouth, 9-II-1713.

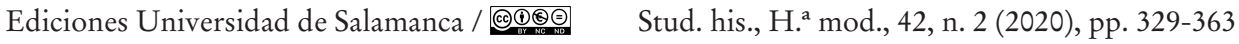


MANUEL ALEJANDRO CASTELLANO GARCÍA

GRAN BRETAÑA Y LA CUESTIÓN CATALANA: LA NEGOCIACIÓN HISPANOBRITÁNICA DURANTE EL FINAL DE LA GUERRA DE SUCESIÓN ESPAÑOLA

en la amnistía además de no suponerle ningún perjuicio le libraría del peligroso e imprevisible comportamiento de unos súbditos ansiosos por recuperar lo perdido ${ }^{47}$.

No solo eso: le informaron que estaban buscando implicar a los plenipotenciarios franceses en defensa de los catalanes ${ }^{48}$, y respecto definir la cuestión como una bagatela se le encargó que, de volver a repetirse, hiciese saber que la reina no lo consideraba tal y que habiendo puesto su honor en juego estaba tan interesada en el mantenimiento de los derechos catalanes como en la propia consecución de la paz ${ }^{49}$.

Pese a todo las instancias de Lexington siguieron mostrándose inútiles. Incluso buscó la complicidad de Bonnac pero éste, que como la mayoría de representantes franceses había perdido gran parte de su crédito ante Felipe V (Désos, 2009: 313), se negó a interceder. Arguyó que solo reforzaría el convencimiento de la corte de que Versalles pretendía dirigir la monarquía hispánica, más aún teniendo en cuenta que Felipe V sospechaba que Luis XIV deseaba que los catalanes conservasen sus privilegios para hacerle depender de su apoyo como contrapeso a la tensión que provocaría en los territorios peninsulares. Además, consideraba tan perdida esa batalla que llegó a escribir a Versalles que Felipe V no aceptaría la conservación de los privilegios catalanes ni aún en situación de extrema necesidad ${ }^{50}$.

Sus continuos fracasos convencieron a Lexington de lo imposible de su misión, proponiendo limitarse a buscar algunos privilegios razonables que salvaguardasen el honor y la autoridad real15. Insistió sobre ello dos semanas después al asegurar que la cuestión de las libertades catalanas, sobre la que pensaba que ya había hecho todo cuanto era posible, era el único punto de la negociación que no estaba a punto de $\operatorname{acordarse} \mathrm{e}^{52}$.

Pero en Londres seguían sin dar su brazo a torcer. En claro tono de reproche Dartmouth le instó a releer sus dos últimas cartas y cerciorarse de que la reina empeñaba en la cuestión su honor y conciencia. Explicó que también a Monteleón se le había asegurado que no pensaban transigir y que, pese a la cautela que éste mostraba, calculaban que habría remitido cartas a Madrid expresando la necesidad

47. N. A. SP 104/133, ff. 112r-113, Dartmouth a Lexington, 13-II-1713.

48. Aunque buscaron apoyo francés (B. L. Add. MS 46547, f. 39, los plenipotenciarios británicos a Lexington, 17-II-1713) parece dudoso que lo lograsen o que, de acceder, estos tuviesen intención real de presionar a Felipe V. Días antes Shrewsbury ya escribió que en Versalles nunca se habían planteado que la amnistía incluyese la conservación de fueros y Luis XIV estaba seguro de que su nieto no transigiría. Argumentaron que en todo caso era decisión de Felipe V, convenciendo a Shrewsbury de que for those poor people nothing can be done here. (En N. A. SP 78/157, ff. 49-50, Shrewsbury a Dartmouth, 13-II-1713).

49. N. A. SP 104/133, ff. 114r-115, Dartmouth a Lexington, 17-II-1713.

50. AMAE, CP Espagne. 220, ff. 80v-81, Bonnac a Versalles, 5-II-1713.

51. N. A. SP 105/270, f. 71, extracto de la carta de Lexington a Dartmouth, 27-II-1713.

52. B. L. Add. MS 46543 A, ff. 155-156, Lexington a Dartmouth, 13-III-1713. 
MANUEL ALEJANDRO CASTELLANO GARCÍA

GRAN BRETAÑA Y LA CUESTIÓN CATALANA: LA NEGOCIACIÓN HISPANOBRITÁNICA

DURANTE EL FINAL DE LA GUERRA DE SUCESIÓN ESPAÑOLA

de ceder. Por ello le ordenó que ante todo no hiciese o dijera nada que pudiera dar a entender lo contrario ${ }^{53}$.

Fuese por tomarlo como una orden de no buscar acuerdos de mínimos o porque no se produjesen más movimientos de entidad, lo cierto es que desde ese momento Lexington pareció centrarse más en los restantes asuntos a negociar, especialmente la conclusión del acuerdo comercial, la cuestión religiosa en Gibraltar y Menorca y el apoyo exigido por Felipe $\mathrm{V}$ a la concesión de una soberanía en Limburgo a la princesa de los Ursinos. De hecho no volvió a comunicar nada sobre la cuestión catalana, mencionándola únicamente al anunciar la firma del acuerdo preliminar de paz y explicar sus artículos, aprovechando para disculparse por no haber sido capaz de conseguir salvaguardar sus leyes ante la firmeza de Felipe V respecto a tal punto ${ }^{54}$.

Efectivamente el artículo 15 del tratado preliminar consagró la concesión de perdón y amnistía a los catalanes pero respetándose únicamente sus vidas, bienes y honores. Se hizo mención expresa a las instancias de Lexington para obtener la restitución de sus leyes, pero añadiendo que no se incluía por considerarlo perjudicial al ejercicio de la soberanía y la quietud del reino. Igualmente reflejó que el británico había accedido a esta resolución para no retardar la paz pero contra sus instrucciones, por lo que la reina de Gran Bretaña no quedaba obligada a aprobar el artículo ni se consideraría que faltaba a su palabra de no hacerlo.

Pese a haberse doblegado a la posición de Felipe $\mathrm{V}$ respecto a la cuestión catalana, Lexington aún sumó un nuevo fracaso cuando en abril Dartmouth le instó a reinsistir. Actuando sin convencimiento alguno e incluso justificando ante Bedmar que únicamente retomaba una cuestión tan desagradable para Felipe V por las órdenes recibidas (Albareda, 2005: 128), el resultado era evidente. Bedmar expresó que, sabiendo cuanto perjudicaría a la monarquía de España la concesión de los privilegios catalanes, esperaban que la reina abandonase su empeño. Más aún comprobando que sacar dicho tema a colación solo servía para entorpecer la conclusión de una paz que garantizaría la tranquilidad y seguridad de Europa y todas las potencias implicadas ${ }^{55}$, argumento que como ya mencionó Storrs (2013: 90) parecía buscar la comprensión británica al vincularlo al mantenimiento de un orden que también Gran Bretaña veía en entredicho a causa del conflicto jacobita y su cuestión sucesoria.

Así pues Lexington se mostró incapaz de variar un ápice la postura de Felipe V respecto a la cuestión catalana, pudiendo calificarse sus gestiones en este sentido de absoluto fracaso. Sabedor de que el resultado final podía ser mal visto en Londres

53. N. A. SP 104/133, f. 123, Dartmouth a Lexington, 13-III-1713.

54. B. L. Add. MS 46543A, f. 53v, Lexington a Bolingbroke y B. L. Add. MS 46543A f. 157, Lexington a Dartmouth, ambas de 28-III-1713.

55. B. L. Add. MS 46549, f. 147, Bedmar a Lexington, 18-IV-1713.

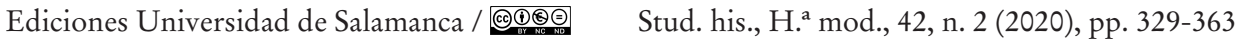


MANUEL ALEJANDRO CASTELLANO GARCÍA

GRAN BRETAÑA Y LA CUESTIÓN CATALANA: LA NEGOCIACIÓN HISPANOBRITÁNICA

DURANTE EL FINAL DE LA GUERRA DE SUCESIÓN ESPAÑOLA

expuso que había luchado tan fuertemente por el respeto a las leyes catalanas que habían llegado a reprocharle que hablaba como un republicano, y que el único motivo por el que había aceptado ese artículo y el relativo a la religión en Gibraltar y Menorca fue por entender que realizaría mejor servicio a la reina firmando bajo esas condiciones que no alcanzando ningún acuerdo global ${ }^{56}$. Porque el de las leyes catalanas no fue su único lunar en la negociación, debiéndose retomar en Londres cuestiones como el mantenimiento de la religión católica en Gibraltar y Menorca. Y aunque la obtención del navío de permiso le supuso un gran punto a favor, no debemos olvidar que el grueso de la negociación comercial recayó sobre el comerciante irlandés Manuel Manasses Gilligan. Incluso Monteleón - a instancias de St. John- llegó a solicitar que Lexington no estuviese enterado de lo tratado en ella ${ }^{57}$, no siendo por tanto suficiente para salvar el resultado global de una actuación diplomática decepcionante.

\subsection{Sellando el destino de los catalanes: el final de la negociación de Monteleón}

La situación para Monteleón era opuesta a la de Lexington, ya que el rápido arreglo del grueso de los temas creó la impresión de que el acuerdo estaba próximo. De hecho el 15 de febrero St. John comentaba su inminencia (Parke, 1798: Vol. III, 375) y el 11 el militar y diplomático Patricio Lawless había llegado para quedar como encargado de negocios de Felipe $\mathrm{V}$ en Londres y sustituir a Monteleón, a quien se esperaba partiendo en breve hacia Utrecht toda vez que los holandeses habían por fin aceptado enviar los pasaportes para los negociadores españoles ${ }^{58}$. Pero St. John le solicitó permanecer hasta concluir el tratado, lo que aceptó alegando que apurando su estancia en la capital británica solucionaría más eficientemente cualquier problema que pudiese surgir (Guerrero, 2008: 491-492).

En el terreno negociador St. John aún pensaba que podrían obtener para los catalanes el respeto a sus leyes y privilegios. Por ello cuando ordenó a Strafford insistir en la rápida expedición de pasaportes a los plenipotenciarios de Felipe V le instó también a mantenerse firme en la cuestión catalana (Parke, 1798: Vol. III, 365) algo que repitió a sus plenipotenciarios en Utrecht, a los que expuso que la reina no abandonaría su petición bajo ninguna circunstancia ${ }^{59}$.

De hecho, en una charla entre Monteleón y Bolingbroke apareció lo que parecía una solución aceptable para ambas partes. Consistía en evitar la expresión Privilegia Omnia, que al englobar todos los privilegios catalanes incluía obligatoriamente las

56. N. A. SP 94/80 s/n, Lexington a Dartmouth, 17-IV-1713.

57. AMAE, CP. Anglaterre. 243, ff. 92v-97, Monteleón a Grimaldo, 19-I-1713.

58. N. A. SP 105/271, los plenipotenciarios británicos a St. John, 14-II-1713.

59. B. L. Add MS 22206, s/n, St. John a los plenipotenciarios británicos, 13-II-1713.

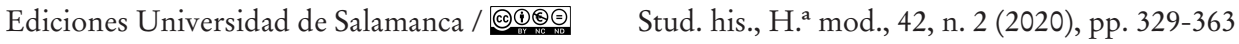


MANUEL ALEJANDRO CASTELLANO GARCÍA

GRAN BRETAÑA Y LA CUESTIÓN CATALANA: LA NEGOCIACIÓN HISPANOBRITÁNICA DURANTE EL FINAL DE LA GUERRA DE SUCESIÓN ESPAÑOLA

leyes aprobadas en las Cortes de 1701 y 1705, empleando en su lugar Privilegia Antiqua, mucho más ambiguo y que podría interpretarse como referido a cualquier privilegio otorgado en tiempo alguno (Albareda, 2015: 85). Esto salvaguardaría el honor británico al incluir la expresión «privilegios» y al mismo tiempo permitiría a Felipe V restringir cuanto quisiera las libertades catalanas. Pero pese a que la satisfacción con este recurso parecía generalizada, los temores de Monteleón de que no fuera aceptado por Felipe V se cumplieron cuando el monarca se negó a incluir nada que pudiese dar pie a una interpretación favorable a los intereses catalanes (Fernández, 2011: 123; Albareda, 2010: 392-393).

Este fracaso aumentó la impaciencia británica y francesa puesto que ya para entonces Bonnac, vista la parálisis negociadora en Madrid, había cifrado sus esperanzas en la actuación de Monteleón en Londres y estaba convencido de que si no presionaban conjuntamente franceses, británicos y holandeses la negociación no acabaría jamás ${ }^{60}$. Este extremo cobraba fuerza cuando entrado el mes de marzo la postura inamovible de Felipe $\mathrm{V}$ respecto a la cuestión catalana obstaculizaba tanto el tratado preliminar hispano-británico como el de evacuación de las tropas imperiales en Cataluña ${ }^{61}$.

La necesidad de desbloquear la situación llevó a una propuesta que sirvió para concluir el segundo de ellos. Se apuntó que, dado que la resolución sobre las libertades catalanas no era esencial para ese acuerdo, podía aplazarse a la negociación de la paz general de Utrecht o al menos a la negociación particular hispano-británica, lo que finalmente fue aceptado.

En la aprobación de este esquema jugó también un papel importante el hartazgo imperial. Sinzendorf ya había planteado que debían dejar de arriesgar el futuro del Imperio por pelear los privilegios de otros y que «de la misma manera que a dos que se ahogan no se puede pedir al que pueda salvarse que se pierda por el otro, así se ha debido abandonar a los catalanes» (Sanpere, 1905: 50). Además, el propio emperador había dado señales claras al encargar a Starhemberg interceder por los catalanes pero sin que sus esfuerzos, ni aun siendo infructuosos, le llevasen a retardar el embarque de tropas (Albertí, 1964: 115).

Este avance permitió que el 14 de marzo se acordase el tratado para la evacuación de Cataluña, cuyo artículo 9 aplazó la cuestión catalana a la conferencia de paz general. Sin embargo presentó un importante añadido al incluir que los negociadores imperiales, británicos y franceses pondrían todo su empeño en asegurar sus privilegios, con lo que Gran Bretaña asumía formalmente el papel de defensora de las libertades catalanas. Por ello Sinzendorf afirmó:

60. AMAE CP. Espagne. 220, f. 109, Bonnac a Torcy, 13-II-1713.

61. AMAE CP. Espagne. 221. ff. 31v-32, Bonnac a Torcy, 13-III-1713.

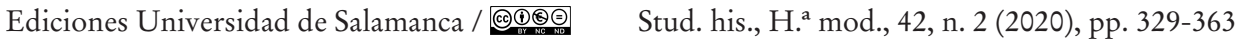


MANUEL ALEJANDRO CASTELLANO GARCÍA GRAN BRETAÑA Y LA CUESTIÓN CATALANA: LA NEGOCIACIÓN HISPANOBRITÁNICA DURANTE EL FINAL DE LA GUERRA DE SUCESIÓN ESPAÑOLA

los catalanes no podrán con razón quejarse de que no se les haya bastante asegurado, pues la Reina de Inglaterra una vez más ha prometido de la manera más solemne y con más viva expresión asegurar la aceptación de sus Privilegios (...) Francia también ha prometido solucionar las pequeñas dificultades que se presentaren ${ }^{62}$.

No todos lo vieron así y otro de los plenipotenciarios imperiales, el conde de la Corzana, se negó a firmarlo por remitir la cuestión catalana a la paz general, apuntando:

el tiempo no borrará el sacrificio que el Ministerio Inglés hace de la España, y singularmente de la Corona de Aragón, y más en particular de la Cataluña, a quienes la Inglaterra ha dado tantas seguridades de sostenerles y ampararles (...) dejando a discreción de la familia de los Borbones la tierra más aliada y distinguida por la causa común, por quienes sus naturales han derramado tanta sangre. Añado a esto que a más de manchar el honor de la Inglaterra aumenta las fuerzas á los Borbones, quedando aquellos países sin Privilegios; y el reservar tratar de este punto á la Paz General es un pretexto muy poco pálido y una esperanza mal fundada porque el opio del Perú y Potosí que de presente a adormecido al ministerio inglés para sacrificar los intereses de los aliados, el honor y la conveniencia de su patria, no ha agotado por este acto las minas y tesoros de los Borbones ${ }^{63}$.

Era obvio que Corzana no sería el único enfadado y por ello Starhemberg mantuvo el tratado en secreto hasta que el 22 de junio ratificó con los borbónicos el Convenio de Hospitalet, que completó los trámites necesarios para la evacuación de las tropas imperiales de Cataluña y convino el alto el fuego total (Albareda, 2002: 117).

Pese a ese avance, la conclusión el 11 de abril de la paz entre Francia y Gran Bretaña-que no incluyó referencia alguna a las reivindicaciones catalanas- redobló la presión británica sobre Monteleón para concluir el preliminar, ya que St. John y Harley querían que la reina pudiese anunciar ambas paces al unísono.

El gran problema de Monteleón era que aún esperaba la respuesta de Madrid a su informe de 5 de febrero sobre las respuestas de la reina a las propuestas sobre los puntos en conflicto, lo que le impedía maniobrar respecto a los puntos en desacuerdo.

Pero ante la insistencia británica y dado que la discusión se reducía a impedir que otras potencias comerciasen en las Indias y resolver la cuestión catalana, decidieron actuar desde la buena fe para evitar «la monstruosidad de que se declarase y publicase la paz particular con la Francia y no se executase lo mesmo por la España». Monteleón temía además que de no anunciarse ambas paces se produjese un vuelco

62. Albertí, S. (1964). L'onze de setembre. Barcelona: Albertí Editor S.L. [Ed. 2006], 50.

63. Castellví i Obando, F. (1997-2002). Narraciones históricas. En J. M. Mundet y J. Alsina (eds.), Vol. III, Madrid: Fundación Francisco Elías de Tejada y Erasmo Pércopo, 520.

Ediciones Universidad de Salamanca / @®@@ Stud. his., H. ${ }^{a}$ mod., 42, n. 2 (2020), pp. 329-363 
MANUEL ALEJANDRO CASTELLANO GARCÍA

GRAN BRETAÑA Y LA CUESTIÓN CATALANA: LA NEGOCIACIÓN HISPANOBRITÁNICA DURANTE EL FINAL DE LA GUERRA DE SUCESIÓN ESPAÑOLA

político que devolviese a los whigs al poder, por lo que decidió aceptar por su cuenta y riesgo un tratado provisional acorde a esas peticiones.

Si bien era relativamente poco problemático aceptar que el comercio de Indias lo realizasen solo los españoles dejando toda puntualización a convenir en Madrid, corría un riesgo mucho mayor al admitir como gracia del rey a la reina Ana la concesión de los antiguos privilegios catalanes. Sabiendo que era contrario a sus órdenes una declaración especificó que, al no tener facultad para acordarlo, quedaba sin valor hasta que Felipe V lo asumiera expresamente. También trató de curarse en salud asegurando a Madrid que había actuado así por ser la única posibilidad de declarar ambas paces y remarcando que dejaba a los británicos a expensas de saber si Felipe V lo aprobaba.

Aún con estas precauciones retrasó la firma hasta el último momento aguardando la llegada de instrucciones. De seguir sin recibirlas, tras firmar esperaría a la apertura del Parlamento para remitir su informe y una copia del tratado provisional, partiendo hacia Utrecht con las últimas respuestas de la corte de Madrid ${ }^{64}$.

Esta decisión resultó clave ya que la reapertura parlamentaria se retrasó sucesivamente al 21, 26 y 28 de marzo y 7 de abril hasta quedar definitivamente fijada para el 20 de abril, permitiendo que en Madrid reaccionasen a la noticia de que Monteleón había aceptado un acuerdo preliminar sin autorización del rey e incluyendo cláusulas que le habían sido expresamente prohibidas.

Bergeyck, firme defensor de no restablecer las leyes catalanas, insistió en que debió haber explicado mejor los «perjuicios irreparables que tendría para su soberanía y la tranquilidad de sus Reinos» y criticó que no hubiese esperado la llegada a Londres del acuerdo preliminar de Madrid para comprobar que no hubiese modificaciones sustanciales o nuevos aspectos a tratar. Tampoco entendía que asumiera riesgo alguno para concluir el acuerdo, pues opinaba que los británicos eran los únicos culpables del retraso al haber bloqueado tanto tiempo la negociación directa entre ambas cortes y estaba convencido de que cualquiera de sus facciones políticas estaría dispuesta a firmar la paz ante los beneficios comerciales que iban a obtener (Muñoz y Catà, 2009: 169-170).

A pesar de ello Felipe $\mathrm{V}$ aceptó su firma del tratado provisional para que la reina anunciase la paz con España y Francia siempre que no obligase a su cumplimiento y quedase a expensas de su posterior aceptación. Además, Grimaldo le informó del acuerdo comercial y adjuntó la copia del preliminar firmado con Lexington, añadiendo instrucciones para negociar los artículos que no habían sido acordados en Madrid y encargándole que remarcara cuanto habían cedido en las cuestiones comerciales para que los británicos fuesen comprensivos en los puntos restantes.

64. AMAE CP. Anglaterre. 244, ff. 93-95, copia de la carta de Monteleón a Grimaldo, 19-III-1713.

Ediciones Universidad de Salamanca / @®@@ Stud. his., H. ${ }^{a}$ mod., 42, n. 2 (2020), pp. 329-363 
MANUEL ALEJANDRO CASTELLANO GARCÍA

GRAN BRETAÑA Y LA CUESTIÓN CATALANA: LA NEGOCIACIÓN HISPANOBRITÁNICA DURANTE EL FINAL DE LA GUERRA DE SUCESIÓN ESPAÑOLA

En lo referente a Cataluña estas instrucciones admitían, de ser recíproco, la restitución y libre disfrute de rentas, bienes y posesiones a los seguidores de Carlos VI, pero únicamente a través de administradores y sin consentir su regreso a Cataluña. No se aceptaba mantener los cargos y beneficios eclesiásticos concedidos por el emperador ya que Felipe V, tras ser asesorado por su confesor y una junta de teólogos, concluyó que no era admisible para su conciencia ${ }^{65}$. Y como era de esperar no varió un ápice su postura respecto a la conservación de los privilegios y leyes catalanas:

en ninguna forma viene ni vendrá en expediente convenio ni Tratado alguno, que mude de lo que tiene determinado y resuelto en esto, manteniéndose firme en la deliberación tomada, sin diferir a la proposición o palabra propuesta de privilegios antiguos ni a otra ninguna (...) en cuanto a los fueros de los catalanes, no viene, ni vendrá S. M nunca, no solo en concedérselos, pero ni aun en admitir, ni convenir, a que se ponga palabra, ni expresión que aluda a ellos, ni les deje ninguna abertura, ni esperanza.

Sostenía que era un punto inamovible por estar en juego su honor y capacidad soberana, ser clave para la seguridad de su monarquía y como consideración a sus fieles vasallos a los que ver repuestos las leyes catalanas «ocasionaría un sumo dolor, viéndose, no solamente iguales con los malos, sino en alguna forma beneficiados más estos, como lo serían los catalanes si se les dejase sus fueros» ${ }^{66}$.

Con estas instrucciones Monteleón solicitó un nuevo encuentro con St. John: el tiempo apremiaba ya que era necesario modificar los aspectos que Madrid consideraba inaceptables antes de la apertura del Parlamento.

En lo referente a Cataluña, si bien St. John mostró su decepción por la cerrazón de Felipe $\mathrm{V}$ su postura presentó un cambio importante al alegar que solo pretendían introducir algún término medio sobre los privilegios. La intención británica ahondaba la línea iniciada al proponer el uso de Privilegia Antiqua, pretendiendo solo añadir algún matiz para salvar el honor de la reina aunque la disposición permitiese a Felipe V acabar con las leyes catalanas ${ }^{67}$.

La cuestión quedó pendiente de una nueva entrevista el 19 de abril en la que Bolingbroke expuso que los ministros de la reina habían encontrado dificultades en

65. AGS, Estado, leg. 6822 Grimaldo a Monteleón, 28-III-1713, citado en Guerrero Villar, J. (2008). El tratado de paz con Inglaterra de 1713. Orígenes y culminación del desmembramiento de la monarquía española (Tesis doctoral). Universidad Autónoma de Madrid, 497-498.

66. AGS, Estado, leg. 6822 Grimaldo a Monteleón, 28-III-1713, citado en Muñoz González, A. y Catà i Tur, J. (2009). La traïció anglesa. Comerç colonial i destrucció de la sobirania catalana (1706-1715). Barcelona: Llibres de l'Índex, 169-170.

67. AMAE, CP. Anglaterre. 244, ff. 222v-223, copia de la carta de Monteleón a Felipe V, 26-IV-1713.

Ediciones Universidad de Salamanca / 요 Stud. his., H. ${ }^{a}$ mod., 42, n. 2 (2020), pp. 329-363 
algunos artículos preliminares firmados en Madrid y tres problemas en el tratado de Asiento. Los problemas eran las condiciones para la cesión de los puertos de Gibraltar, Menorca y Mahón, la salvaguarda de la religión católica en dichas plazas y, por supuesto, la cuestión catalana.

Respecto a Cataluña, insistieron en encontrar una solución que conservase el honor de la reina sin perjudicar la intención de Felipe $\mathrm{V}$ de establecer una única ley en todos sus dominios. Tras exponer Monteleón que el rey rechazaba el término «privilegios antiguos».por saber que los catalanes aprovecharían cualquier alusión a sus leyes y privilegios para mantener su actitud sediciosa, propuso una nueva solución. Junto a vida, bienes y honores se les dejarían sus leyes civiles salvo aquellas leyes y privilegios opuestas a la soberanía y regalía, concediéndoles el mismo trato que a aragoneses y valencianos y pasando a gozar de todos los privilegios castellanos. Bolingbroke, deseoso de acordar un punto tan problemático, se comprometió a hacer lo posible por conseguir un acuerdo.

Ante la preocupación por lo que acontecería al anunciarse al día siguiente que la negociación con España no había concluido Monteleón volvió a actuar de forma autónoma. Aseguró que dada la buena fe de ambas partes se comprometía a allanar cuanto pudiese las dificultades y confiaba en que Felipe V aprobaría el servicio que realizaba por concluir la paz. Por ello podían anunciar al Parlamento que la paz con España también había sido finalizada, una solución improvisada que agradecieron tanto la reina como su Consejo Reallo.

Pero pese a salvarse el trámite de la apertura parlamentaria el acuerdo seguía sin finalizarse, y el 22 de abril St. John volvió a insistir en la necesidad de concluirlo para evitar el fracaso de la negociación:

il est absolument nécessaire que nous trouvions quelque tempérament sur l'article des Fueros des Catalans, E sur celui de la religion dans l'Isle de Minorque É à Gibraltar. Il seroit en vérité, Monsieur, trop dur, de voir une négociation, conduite jusques ici si heureusement, accrochée par des bagatelles, j'ose appeller ainsi tout ce qui arrête la conclusion de la pax entre nos deux nations.

Expuso que aunque la reina había mantenido una posición muy rígida traía una posibilidad para cerrar las cuestiones religiosa y catalana al unísono: consentiría el artículo sobre los privilegios catalanes sugerido por Monteleón si este aceptaba resolver la cuestión religiosa en Menorca y Gibraltar con una estipulación genérica garantizando su libre ejercicio y conservación ${ }^{69}$.

68. Ibidem, ff. 223-226v.

69. Parke, G. (ed.). (1798). Letters and correspondence... op. cit., Vol. IV, 33-36, St. John a Monteleón, 11/22-IV-1713. La cita en las págs. 33-34.

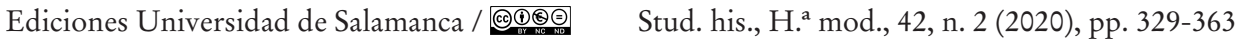


MANUEL ALEJANDRO CASTELLANO GARCÍA

GRAN BRETAÑA Y LA CUESTIÓN CATALANA: LA NEGOCIACIÓN HISPANOBRITÁNICA DURANTE EL FINAL DE LA GUERRA DE SUCESIÓN ESPAÑOLA

Tras reafirmar que la intención de Felipe $\mathrm{V}$ era alcanzar un acuerdo agradable para la reina Monteleón volvió a razonar los puntos de desencuentro. De las leyes catalanas aseguró que el rey no toleraría términos medios porque solo eliminándolas podría garantizar el buen gobierno de sus territorios, insistiendo en la fórmula de otorgar perdón y ofrecer los privilegios castellanos. Concluyó afirmando que viendo la importancia que Felipe $V$ daba a este punto la mayor muestra de amistad que podían ofrecer sería dejar de insistir en la conservación de las leyes catalanas ${ }^{70}$.

Finalmente, en una nueva conferencia con Bolingbroke, se le comunicó que tras varias reuniones el Consejo Real había resuelto consentir excluir las leyes y privilegios catalanes y aceptar que les fuesen concedidas las que disfrutaban los súbditos castellanos.

El momento de conseguir este avance definitivo era de enorme trascendencia puesto que en esas fechas y tras pasar sin fortuna por Viena, Utrecht y La Haya, había llegado a Londres Francesc de Berardo, marqués de Montnegre. Su misión era garantizar los derechos catalanes y defender la conformación de una república del Principado de Cataluña, aunque ya desde enero de 1713 había sido instruido para que en el peor de los casos, de quedar bajo dominio borbónico se reconociesen las constituciones y privilegios concedidos por Carlos II y las leyes de Aragón, Valencia y Mallorca (Albareda, 2000: 71-72).

Pero Monteleón había conseguido introducir entre sus hombres de confianza al alicantino Pascual Antón, y gracias a ello pudo informar a St. John de su presencia e intenciones. De esta manera cuando Montnegre solicitó audiencia se le respondió que sin una carta de Felipe $\mathrm{V}$ o ser presentado por el embajador español solo podría ser recibido a título personal y sin reconocérsele autoridad diplomática, como finalmente sucedió durante el mes de mayo y sin el menor éxito para los intereses del embajador catalán.

También otro de los embajadores catalanes, Pau Ignasi de Dalmases, apoyado por los políticos británicos Mitford Crowe, James Stanhope y Charles Mordaunt, conde de Peterborough, fue recibido por la reina y presentó varias instancias de intercesión en favor de los catalanes, entre ellas una súplica ante ambas Cámaras parlamentarias, sin lograr tampoco el resultado deseado (Albareda, 2010: 395-397).

Por todo lo anterior y ante la necesidad apremiante de concluir la negociación -se esperaba en breve la llegada de los tratados firmados en Utrecht, que junto con el preliminar con España quedarían a disposición del Parlamento-Monteleón aceptó firmar el preliminar de paz pese a sus reticencias en el tema de la religión. Afirmó

70. AMAE, CP Anglaterre. 244, ff. 230-231, Copia de la carta de respuesta del marqués de Monteleón a la carta de Milord Bolingbroke, 26-IV-1713.

Ediciones Universidad de Salamanca / @®@@ Stud. his., H. ${ }^{a}$ mod., 42, n. 2 (2020), pp. 329-363 
MANUEL ALEJANDRO CASTELLANO GARCÍA

GRAN BRETAÑA Y LA CUESTIÓN CATALANA: LA NEGOCIACIÓN HISPANOBRITÁNICA DURANTE EL FINAL DE LA GUERRA DE SUCESIÓN ESPAÑOLA

que así podría pasar a Utrecht con la amistad y apoyo británico, dejando además a Felipe V la libertad de decidir si aceptaba o no esos términos ${ }^{71}$.

Su opinión era compartida en Francia, y Torcy le escribió felicitándole por cerrar el acuerdo sobre Cataluña, añadiendo que haberse empeñado en alargar la discusión de puntos que no merecían tanta atención habría sido realizar un mal servicio a Felipe V aunque el monarca «no pareciese estar convencido de esta verdad» ${ }^{72}$.

Sin embargo la negociación aún se prolongó con tres nuevas reuniones del Consejo Real en las que participó Monteleón. El punto principal era la cuestión religiosa, pero se siguió abordando el caso catalán ante las reticencias de la reina a que concluyesen la guerra en peor condición de como la empezaron. En esos momentos Bolingbroke jugó un papel decisivo al persuadirla de la bondad de la solución pactada, argumentando que los privilegios castellanos les serían más beneficiosos por ser más prácticos para todo pueblo que quisiera vivir en la debida sujeción a la autoridad real (García 1998: 423-425).

En la primera reunión, celebrada el 28 de abril, tras recordar a Monteleón lo urgente que era cerrar definitivamente un acuerdo pasaron a discutir los dos artículos en disputa. Sobre la cuestión catalana los británicos insistieron en que para salvar el honor de la reina debía constar en la redacción del artículo la expresión «privilegios antiguos», pero Monteleón reiteró que no estaba autorizado a aceptarlo ya que los catalanes, proclives a la sedición, lo usarían para alegar más adelante que el rey había faltado a lo prometido. Incidió en «lo exorbitado de sus privilegios frente a la autoridad real y las desgracias que habían supuesto a España» y cómo eliminarlos permitiría el buen gobierno y reforzaría la independencia española respecto a Francia al refrenar a unos vasallos que habían demostrado ser tan peligrosos, apelando incluso al ejemplo de la unión de Inglaterra y Escocia para defender su postura.

Si bien sus interlocutores apoyaban mayoritariamente «que el Rey de España para su quietud e independencia debía desear que sus vasallos se gobernasen bajo unas leyes comunes y no contrarias a su real autoridad» temían que si el acuerdo final no mencionaba expresamente sus privilegios los defensores de la causa catalana, capitaneados por Peterborough entre los Lores y Stanhope en los Comunes, pudieran causar problemas en el Parlamento. Al no lograr un acuerdo consensuado, tras realizar algunos apuntes sobre los restantes artículos se decidió que Monteleón y Bolingbroke buscasen una solución aceptable y pusieran en limpio todo el tratado. Tras ello y sabiendo las últimas decisiones de la reina sobre los dos puntos en disputa, concluirían definitivamente el acuerdo preliminar en una última reunión.

71. AMAE, CP. Anglaterre. 244, ff .227v-228, copia de la carta de Monteleón a Felipe V, 26-IV-1713.

72. AMAE, CP. Anglaterre. 244, f. 232, copia de la carta de Torcy a Monteleón, 2-V-1713.

Ediciones Universidad de Salamanca / 요 Stud. his., H. ${ }^{a}$ mod., 42, n. 2 (2020), pp. 329-363 
MANUEL ALEJANDRO CASTELLANO GARCÍA

GRAN BRETAÑA Y LA CUESTIÓN CATALANA: LA NEGOCIACIÓN HISPANOBRITÁNICA

DURANTE EL FINAL DE LA GUERRA DE SUCESIÓN ESPAÑOLA

En efecto, del 28 de abril al 1 de mayo Monteleón -además de reunirse en privado con los restantes miembros del Consejo para predisponerlos a aceptar su postura- buscó con Bolingbroke un entendimiento en los dos puntos conflictivos y juntos realizaron un borrador del acuerdo preliminar de paz.

En el consejo del 1 de mayo se leyó íntegramente dicho borrador, incluyendo sobre la marcha las modificaciones necesarias en caso de que apareciesen problemas o matices que incluir.

El artículo 13 era el referente a la amnistía y las leyes catalanas. St. John expuso que la reina no se oponía a las razones presentadas por Monteleón pero que debía articularse dejando su honor a resguardo. Insistió en que eso solo se alcanzaría incluyendo en el texto la palabra "privilegios», siendo algo que Felipe V debía conceder y más tras el importante papel que la reina había jugado a la hora de acordar el tratado de evacuación de Cataluña. Tras un intenso debate Monteleón consiguió que el artículo expresara que, tras realizar Ana de Gran Bretaña todos los esfuerzos para que los catalanes consiguiesen perdón y amnistía general con la conservación de bienes, honores y sus antiguos privilegios, el rey de España en atención a ella no solo les concedía el perdón y conservación de bienes y honores sino también todos los privilegios que los pueblos de Castilla gozaban ese momento y tendrían en el futuro.

El éxito de Monteleón en este punto fue total. Había logrado excluir las leyes catalanas permitiendo al mismo tiempo a los británicos afirmar haberles conseguido los mismos privilegios que a los castellanos. Así, mientras Bolingbroke afirmaba que los términos se habían plasmado de la forma más suave y favorable posible para los españoles de acuerdo con la dignidad y el honor de la reina ${ }^{73}$, Monteleón, exultante, aseguró «yo mismo no sé cómo he podido reducir a esta gente a esto, y que solo la fuerza de la razón del rey y una respetuosa entereza sin que pareciese resistencia a sus empeños lo ha logrado vencer».

Con todo ya acordado solo quedó esperar la llegada del secretario del obispo de Bristol con el tratado franco-británico, momento en que Monteleón fue convocado a un último consejo real donde se firmó el acuerdo preliminar de paz. Posteriormente leyeron las instrucciones a los plenipotenciarios británicos, que para gran satisfacción de Monteleón les instaban a ayudarlo en cuanto precisara y tratarlo con toda confianza ${ }^{74}$.

Cumplida su misión Monteleón pasó a Utrecht para rematar la paz. Se esperaba que su llegada llevase a una firma casi inmediata eliminando las objeciones presentadas por el duque de Osuna, muy poco estimado por el resto de diplomáticos y

73. N. A. SP 105/270, ff. 107-108, St. John a Dartmouth, 8-V-1713.

74. AMAE, CP. Anglaterre. 245, ff. 87-97, copia de la carta de Monteleón a Grimaldo, 22-V-1713.

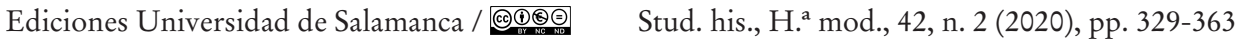


MANUEL ALEJANDRO CASTELLANO GARCÍA

GRAN BRETAÑA Y LA CUESTIÓN CATALANA: LA NEGOCIACIÓN HISPANOBRITÁNICA DURANTE EL FINAL DE LA GUERRA DE SUCESIÓN ESPAÑOLA

considerado una figura ornamental pese a su condición de negociador principal $^{75}$. De hecho Osuna no solo tuvo roces con los plenipotenciarios de las restantes potencias y pronto chocó también con Monteleón por su muy distinta concepción sobre los acuerdos alcanzados en Londres y cómo encarar las negociaciones en Utrecht. Esta situación, si bien aumentada por las pretensiones maximalistas y poco realizables de Osuna, según Reyes Fernández (2011: 128, 130) se debió principalmente a que mientras este velaba únicamente por los intereses españoles la concesión a Monteleón de una renta vitalicia sobre el asiento de negros para su hija le había hecho mucho menos beligerante respecto a las peticiones británicas. Además Monteleón pretendió manejar personalmente las negociaciones con Holanda y Portugal, comunicando a Osuna a su llegada que tenía instrucciones concretas de Felipe V para llevarlas a cabo pero negándose a mostrárselas pese a ser el plenipotenciario principal.

Los constantes desplantes y ataques de Monteleón llegaron a sumir a Osuna en un cuadro depresivo y marcó el inicio de una relación tan mala que devino en abierta enemistad. La situación llegó al extremo que, ya firmada la paz con Gran Bretaña y mientras se trataban los acuerdos con Holanda y Portugal, sus frecuentes $\mathrm{y}$ violentas discusiones incluso en presencia de los representantes de otras potencias supusieron tal escándalo que obligaron a Felipe $\mathrm{V}$ a escribirles llamándoles al orden (Albareda, 2015: 89).

En cuanto a las expectativas catalanas, su situación era desesperada. Si desde 1711 temían haber sido dejados militarmente indefensos (Torras, 2000: 80-83; 2013: 137), la firma en verano de 1712 del cese de hostilidades de los borbónicos con Gran Bretaña y meses después con Portugal hizo que para finales de año solo contasen con las tropas del emperador para defender el territorio. Cierto es que para Portugal fue un armisticio forzado por su dependencia de los británicos, del que no obtuvieron beneficios y que preludió su desengaño en Utrecht a obtener una barrera defensiva peninsular (Martín, 2014: 81-82), pero que su retirada fuese planificada y avituallada por la corte borbónica (Cases, 2013: 47-49) muestra hasta qué punto ambos bandos veían lo vital de los armisticios para el futuro de la campaña catalana.

También el apoyo del emperador parecía flaquear. Pese a que Carlos VI creó en Viena una Junta para tratar los asuntos peninsulares en 1712 prohibió sucesivamente la consulta de empleos para Castilla y los territorios italianos, lo que unido a una mayor conflictividad social y al aumento de quejas por abusos de las

75. B. L. Add. MS 46546, f. 89, Plenipotenciarios a Lexington, 22-V-1713. Sobre las objeciones del duque de Osuna ver Albareda, J. (2015). Los tratados de Utrecht-Rastatt y España: ceder lo mínimo para conservar lo principal. En J. Albareda (ed.), El declive de la monarquía y del imperio español: los tratados de Utrecht, (1713-1714). Barcelona: Crítica, 88-89 y Fernández, R. (2011). La corona española y el tráfico de negros: del monopolio al libre comercio. Madrid: Ecobook, 126-127. 
MANUEL ALEJANDRO CASTELLANO GARCÍA

GRAN BRETAÑA Y LA CUESTIÓN CATALANA: LA NEGOCIACIÓN HISPANOBRITÁNICA DURANTE EL FINAL DE LA GUERRA DE SUCESIÓN ESPAÑOLA

tropas imperiales marcó un progresivo distanciamiento entre autoridades catalanas e imperiales (León, 2013: 111-115, 2015: 228). Esto aumentó el miedo catalán a quedar totalmente abandonados, especialmente cuando desde inicios de 1713 un constante goteo de informes advertían del repliegue imperial de zonas estratégicas que inmediatamente después y casi a modo de relevo posicional pasaban a manos borbónicas (Torras, 2013: 144; 2015: 300). No extraña por tanto la tensión provocada por la noticia de la marcha de la emperatriz, que aunque finalmente se realizó con enorme boato el 19 de marzo vivió jornadas previas de enorme tensión en las que incluso se llegó a plantear impedir su embarque (García, 2014: 153). Con ella marchó a Viena la mayor parte de cortesanos y miembros de la administración en Barcelona, y pese a que la emperatriz realizó un decreto organizando el gobierno como si fuese a perdurar tras su partida (León, 2003: 206) su partida supuso la casi completa desarticulación de la administración austracista en Cataluña. Esta quedó en manos de Starhemberg, quien trató de convencer a figuras de importancia en Barcelona de retomar la obediencia a Felipe $\mathrm{V}$ para predisponer al monarca a una mayor clemencia (Albareda, 2010: 366) y confirmó la evacuación de las tropas imperiales de Cataluña con la mencionada firma del Convenio de Hospitalet antes de abandonar la ciudad de incógnito y embarcarse con sus tropas el 9 de julio.

No eran mejores las expectativas catalanas en el terreno diplomático. Ya al poco de iniciarse el congreso de Utrecht Sinzendorf denunciaba «la grande unión y armonía que hay entre los ministros de Inglaterra y Francia» (Albareda, 2010: 323) y el conde de Gallas, embajador imperial en La Haya, afirmó que su secretario había presenciado como franceses y británicos trabajaban juntos ${ }^{76}$. Las protestas de la diplomacia imperial no andaban demasiado desencaminadas: Luis XIV había ordenado a sus negociadores que, sin caer en la total complacencia, contentasen en todo lo posible a los británicos (Bluche, 1998: 307-308), y el vuelco diplomático era tan obvio que a mediados de año uno de los plenipotenciarios franceses, el abbé de Polignac, comentó a Torcy que la situación había cambiado tanto respecto a Gertruydenberg que suponía para ellos una venganza casi completa por el trato sufrido allí por parte de los holandeses (Torcy, 1757: 250).

La unión franco-británica y su interés compartido por finalizar la paz lo antes posible no auguraba nada bueno para los intereses catalanes, como se confirmó a mediados de 1712 cuando el plenipotenciario imperial Hoffman buscó garantizar sus leyes y constituciones y recibió la respuesta de que Felipe $\mathrm{V}$ antes que otorgarlos arriesgaría nuevas campañas militares (Albertí, 1964: 111). En vista de ello buscó acordar con los restantes aliados la creación como república del Principado de Cataluña, pero Bolingbroke se negó en redondo alegando que su existencia provocaría constantes guerras y haría víctimas continuas a aquellos a quienes pretendía defender 
MANUEL ALEJANDRO CASTELLANO GARCÍA

GRAN BRETAÑA Y LA CUESTIÓN CATALANA: LA NEGOCIACIÓN HISPANOBRITÁNICA

DURANTE EL FINAL DE LA GUERRA DE SUCESIÓN ESPAÑOLA

(García 1998: 422). De hecho, Bolingbroke estaba decidido a que esta cuestión no encallase por más tiempo las negociaciones y había comunicado a sus plenipotenciarios que mantener los privilegios catalanes solo lograría que la Corona española dependiese de Francia para asegurar la tranquilidad de esa zona o Cataluña se lanzase en brazos franceses como apoyo contra Felipe V (Albareda, 2005: 129). Ninguna de las opciones le parecía conveniente para Gran Bretaña, dejando bien claro: It is not for the interest of England to preserve the Catalan liberties (Soldevila, 1995: 23).

Además Utrecht fue en esencia un Congreso de alcance limitado, constreñido a ratificar lo negociado de antemano entre Francia y Gran Bretaña y sin producirse grandes cambios ni negociaciones clave, lo que ha llevado a Lucien Bély (2007: 503-524) a calificarlo como un «teatro para la paz». No es de extrañar pues que pese a aparecer algunos puntos de fricción inesperados -especialmente la exigencia de Felipe $\mathrm{V}$ de ser reconocido en el preámbulo del tratado como soberano de los territorios que iba a ceder, el intento de incluir en el tratado principal lo referente al principado de la princesa de los Ursinos y la intención británica de resolver algunas peticiones portuguesas- la cuestión catalana no fuese replanteada.

Así el 13 de julio se firmó la paz entre Gran Bretaña y España sin modificaciones respecto a lo suscrito en Londres sobre las libertades catalanas, limitándose su artículo 13 a garantizar la vida y bienes de los catalanes y la concesión de «los privilegios que poseían los habitantes de las dos Castillas».

Finalizaba con ello la negociación hispano-británica, pero si bien el acuerdo acabó en gran medida con la posibilidad del mantenimiento de las libertades catalanas no significó el fin del debate sobre ellas. Ni la paz hispano-británica ni el Congreso de Utrecht cerraron la cuestión catalana, retomada en Rastatt y Baden e incluso en 1725 con la firma de la paz entre España y el Imperio. Más aún, la paz hispano-británica ni siquiera solucionó el debate sobre la actitud tomada en relación a los catalanes en la propia Gran Bretaña.

\section{UN ASUNTO INACABADO. LA CUESTIÓN CATALANA EN GRAN BRETAÑA TRAS UTRECHT}

Pese a ser la gran beneficiaria de los acuerdos alcanzados la paz abrió una profunda crisis política en Gran Bretaña agudizada cuando los whigs lograron el rechazo parlamentario del acuerdo comercial con Francia por 194 votos contra 185 , asunto que siguieron usando contra el gobierno durante buena parte de 1714 . A esto se añadió un repunte de la crisis interna tory, donde un nuevo intento de Bolingbroke de remodelar el gobierno para hacerlo estrictamente conservador significó su definitiva ruptura con Harley, que aprovechó para moverlo a Secretary of State for the Southern Department y alejarle de las decisiones vinculadas con Hannover y la sucesión a la corona británica (Hoppit, 2000: 308). La fractura tory

Ediciones Universidad de Salamanca / @®@@ Stud. his., H. ${ }^{a}$ mod., 42, n. 2 (2020), pp. 329-363 
MANUEL ALEJANDRO CASTELLANO GARCÍA

GRAN BRETAÑA Y LA CUESTIÓN CATALANA: LA NEGOCIACIÓN HISPANOBRITÁNICA DURANTE EL FINAL DE LA GUERRA DE SUCESIÓN ESPAÑOLA

en este sentido era total, y pese a vencer ampliamente en las elecciones de 1713 se encontraron con que al menos 80 de sus parlamentarios eran jacobitas a ultranza frente a un mínimo de 75 profundamente hannoverianos, todo ello mientras el elector de Hannover desconfiaba cada vez más de un Harley que aún a finales de 1713 promovía propaganda jacobita (Gregg, 2001: 364, 368-369).

El caso catalán también fue usado para arremeter contra los tories, más aún cuando el gobierno británico confirmó el abandono de sus antiguos aliados al sumar su flota al bloqueo de Barcelona y encargar Bolingbroke al almirante Wishart que de no rendirse Barcelona y Mallorca procediese a someter «a ese pueblo turbulento» (Soldevila, 1995: 24).

Ante esta situación el 3 de abril Lord Cowper suplicó a la reina en nombre de 24 lores renovar sus instancias para garantizar a los catalanes el disfrute total de sus libertades. Durante dos días de acalorado debate los whigs solicitaron hacer público todo documento relativo a la paz, atacaron la labor realizada por Lexington e incluso emplearon sus instrucciones sobre la cuestión catalana y las referencias a estar empeñados en la causa catalana el honor y la conciencia de la reina para justificar seguir presionando a Felipe V por su conservación. Pero el intento whig resultó estéril al responder la reina que ya había procurado el mantenimiento de las libertades catalanas y trasladar al emperador la responsabilidad de seguir insistiendo en ellas (Albareda, 2000: 73-74, 2010: 400-401). En línea con estos ataques contra la actuación tory, en la primera mitad de 1714 se editaron los panfletos The deplorable bistory of the Catalans y The case of the Catalans Considered:

If they are Rebels, we are last People should call them so, since it was mostly by our Persuasions, that that People were drawn from their Obedience (...) I have a great regard for the Honour of my Country (...) I would not have it said that then we abandon'd a People to be Destroy'd, for the Crime of adhering our Interest, or following those Measures in Politicks, which we inculcated as Loyal and Just (...) In Case of another War, what People will rely on British Word?77.

Semejante contexto de inestabilidad política profundizó la pérdida de confianza de la reina Ana en Harley: desde finales de 1713 sus reuniones eran cada vez más infrecuentes, y cuando sucedían la propia monarca se quejaba de no entenderle (Gregg, 2001: 374-379). Unido al continuo ataque whig, el desencanto jacobita con Harley por su inacción para favorecer las opciones de un Jacobo Estuardo que, además, rechazó definitivamente convertirse al anglicanismo para optar al trono y la guerra abierta entre Harley y Bolingbroke, culminó con la pérdida de Harley de su puesto de Lord High Treasurer, que pasó a Charles Talbott, duque de Shrewsbury (Hill, 1988: 209-221).

77. (1714). The case of the catalans consider'd. Londres: J. Baker, 17, 25-26, 29.

Ediciones Universidad de Salamanca / @®@@ Stud. his., H. ${ }^{a}$ mod., 42, n. 2 (2020), pp. 329-363 
MANUEL ALEJANDRO CASTELLANO GARCÍA

GRAN BRETAÑA Y LA CUESTIÓN CATALANA: LA NEGOCIACIÓN HISPANOBRITÁNICA DURANTE EL FINAL DE LA GUERRA DE SUCESIÓN ESPAÑOLA

Esta convulsa situación unida al fallecimiento de la reina el 1 de agosto de 1714 favoreció una causa catalana que parecía herida de muerte desde que en Rastatt fracasó su última gran opción. Eugenio de Saboya, que consideraba una traición abandonar a los catalanes (Henderson, 2002: 218), obtuvo a cambio del principado en Limburgo para la princesa de los Ursinos un artículo que permitiría al emperador, sin romper la paz con Francia, asistirles económica y militarmente hasta lograr amnistía general y el reconocimiento de sus libertades en igual pie que en tiempos de Carlos II. El plenipotenciario francés, mariscal de Villars, lo aceptó arguyendo que, sin apoyo de las potencias marítimas, solo serviría para permitir al emperador asegurar haber hecho todo lo posible por los catalanes (Albareda, 2010: 348-351) pero fue desautorizado por Torcy, que se negó a ratificarlo siendo el artículo suprimido del acuerdo final (Bély, 1990: 666-667).

Pero una vez sucedido el cambio dinástico la antipatía por los tories del nuevo monarca, George de Hannover, amenazaba con retornar a los whigs al poder y tal vez reavivar la guerra contra Felipe V, aún mantenida por Carlos VI.

De hecho, el Consejo de Regencia además de suspender las incipientes negociaciones para realizar un tratado defensivo con Francia instó a Prior a solicitar a Torcy un tratado que asegurase la rendición de Barcelona, reclamando un cese de hostilidades hasta entonces y amenazando con consecuencias de persistir la idea de someterla militarmente. En vista de que las potencias volvían a interesarse por los catalanes Luis XIV, que ya en 1713 retuvo las tropas que enviaba a Felipe V para ayudarle a tomar Barcelona como medio de presionarle para firmar la paz con Holanda (Guillamón y Muñoz, 2008: 202-203, carta CLXXV), le insistió en finalizar el asedio de Barcelona permitiendo una capitulación razonable a sus habitantes aunque no les devolviese sus privilegios (Guillamón y Muñoz, 2008: 208, carta CLXXX).

Ante esta situación Dalmases solicitó al Consejo de Regencia el envío de la flota británica para garantizar la suspensión de hostilidades y el aprovisionamiento de Barcelona hasta la paz. En esta ocasión sí fue escuchado y a principios de septiembre se ordenó a la flota dirigirse a Mahón, pero los tories frenaron la actuación alegando que era una decisión que solo correspondía al rey y debían esperar a que lo autorizase personalmente una vez llegase a Gran Bretaña (Albareda, 2002: 123-126). Además, el 18 del mismo mes Felip Ferrán, embajador catalán en Holanda, pudo entregar en mano a George I una petición de intermediación que presentaba diversas soluciones a la cuestión catalana, y su secretario Jean de Robethon le comentó pocos días después que Cataluña estaría salvada si Barcelona aguantaba hasta el retorno del rey a Londres, extremo del que sin embargo difería Bolingbroke, convencido de que el Parlamento no permitiría que Gran Bretaña volviese a entrar en conflicto (Albareda, 2010: 407-408, 412). 
MANUEL ALEJANDRO CASTELLANO GARCÍA

GRAN BRETAÑA Y LA CUESTIÓN CATALANA: LA NEGOCIACIÓN HISPANOBRITÁNICA DURANTE EL FINAL DE LA GUERRA DE SUCESIÓN ESPAÑOLA

Sea como fuere no hubo posibilidad de comprobarlo. El 11 de septiembre Barcelona fue tomada por las tropas borbónicas y el monarca británico no llegó a las islas hasta el 29, convocando además unas nuevas elecciones que, pese a dar la mayoría a los whigs por 341 a 217, retrasó la apertura del Parlamento hasta el 25 de marzo de 1715 (Hoppit, 2000: 389-391). La caída de Barcelona aclaró un contexto de gran incertidumbre dada la simpatía con que los whigs y el nuevo rey veían la causa catalana puesto que, como afirmó Monteleón, de no haber sucedido los británicos habrían vuelto a hacer fuerza para conseguir el restablecimiento de sus privilegios ${ }^{78}$.

Sin embargo y pese a la inquietud que aún conservaron por un tiempo los borbónicos, los británicos no presentaron mayor interés en reavivar la cuestión, manteniendo total pasividad durante la toma de Mallorca, que acabó con la resistencia a Felipe V.

Para lo que sí se empleó fue como parte de un último ataque -tal vez una venganza política- al establecerse un Committee of Secrecy que buscó depurar responsabilidades entre los tories que dirigieron a Gran Bretaña hacia la paz. Su resultado fue un informe que, al hacer referencia a la cuestión catalana, se mostró muy crítico con la actuación realizada. Resolvió que los ministros británicos no se emplearon debidamente para salvaguardar el honor y la palabra dada por la reina, y abandonaron la cuestión finalizándola de forma agradable para los intereses de Felipe V e incluso dando muestras -especialmente Bolingbroke- de desinterés y desprecio hacia los aliados catalanes. Concluyeron pues, que si bien había sido una actuación impropia «the Calamities of the Catalans, will not be imputed to GreatBritain in general, abused by the Ministry, wich repeated Assurances, that every thing was doing for the Preservation of that unfortunate People» ${ }^{79}$.

Como resultado del Committee of Secrecy se acusó de alta traición a Robert Harley, Bolingbroke y al duque de Ormonde -el primero estuvo dos años preso en la torre de Londres antes de ser declarado inocente y los dos restantes se exiliaron a Francia- y a Strafford de high crimes and misdemeanors, cargos que tampoco fueron probados. También Lexington fue duramente criticado por su débil actitud negociadora, su escaso cumplimiento de las órdenes recibidas y haber tratado posteriormente a los catalanes como rebeldes ${ }^{80}$, y si bien no fue formalmente acusado tampoco volvió a ocupar desde entonces cargo alguno, desapareciendo de la vida pública hasta su fallecimiento (Storrs, 2013: 98-99).

78. AMAE, CP. Anglaterre. 260, f. 33, Monteleón (sin destinatario, probablemente la corte), 30-XI-1714.

79. (1715) A report from the Committee of Secrecy, appointed by order of the House of Commons to examine several books and papers laid before the House, relating to the late negotiations of Peace and Commerce, reported on the Nine of June, Londres: Thomas Hume, 85-98. La cita en la página 98.

80. Ibidem, 84-89. 
MANUEL ALEJANDRO CASTELLANO GARCÍA

GRAN BRETAÑA Y LA CUESTIÓN CATALANA: LA NEGOCIACIÓN HISPANOBRITÁNICA

DURANTE EL FINAL DE LA GUERRA DE SUCESIÓN ESPAÑOLA

\section{CONCLUSIONES}

El caso catalán resulta paradigmático tanto en el sentido de mostrar la adopción de un pragmatismo político por encima del cumplimiento de los compromisos adquiridos con los propios aliados -algo que en la guerra de Sucesión española pudo verse también en el lado francés con su abandono a húngaros y jacobitas ${ }^{81}$ - como de ejemplo de cómo la obcecación de un rey un punto concreto podía llegar incluso a poner en riesgo la totalidad de una negociación.

En lo que se refiere a Gran Bretaña, su posición pasó de la absoluta firmeza a plantear y aceptar una solución puramente estética que permitiese salvar su honra aún a costa de los intereses de su aliado. Paradójicamente solo Lexington mantuvo una línea constante. No valoramos con ello su capacidad como negociador, habiendo ya comentado lo decepcionante de su actuación, sino la sinceridad de sus actos. Y es que si bien una vez firmada la paz no tuvo reparos en aconsejar a los borbónicos movimientos de tropas para mitigar la rebelión catalana y a los propios catalanes la rendición (Cobbet, 1810: Apéndices CCVII n. 53 y CCX n. ${ }^{\circ}$ 57), había asumido desde el primer momento la postura felipista insistiendo en la salvaguarda de las leyes y constituciones catalanas únicamente a instancias de Londres. Por el contrario, los interlocutores de Monteleón pasaron de la defensa de los intereses aliados a dar órdenes directas para su abandono y limitarse a conseguir ese matiz que salvaguardase el honor de la palabra dada.

Cierto es que actuaron acorde a lo que aconsejaba el pragmatismo político. Habiendo obtenido ya los frutos que deseaban de la paz, esencialmente ventajas comerciales, era a todas luces una mala idea alargar la negociación enfrentándose a un convulso escenario interior marcado por el feroz reavivamiento de los enfrentamientos entre partidos y la cada vez más cercana sucesión al trono. Más aun en un ambiente de ruptura con sus antiguos aliados y ante la cerrazón de un Felipe V capaz de bloquear una paz que necesitaba para no ceder en un punto que consideraba personal. Y si también es cierto que de haber sucedido antes el cambio ministerial y de monarca tal vez podría haberse modificado el sentido de esta actuación, no lo es menos que cuando finalmente aconteció únicamente se realizaron declaraciones de apoyo a la causa catalana y tras consumarse la caída de Barcelona no se volvieron a plantear actuaciones en su favor.

La actuación de Felipe V es otro importante punto a destacar. Pudiendo por fin actuar con voz propia, aunque es innegable que tuvo menos capacidad de actuación

81. Ver Bély, L. (2015). Ombres et lumieres dans l'Europe de la paix d'Utrecht (17131714). En C. Mollfulleda y N. Sallés (eds.). Els Tractats d'Utrecht clarors i foscors de la pau, la resistència dels catalans: 9-12 de abril, actes del congrés (pp. 19-25). Barcelona: Museu d'Historia de Catalunya.

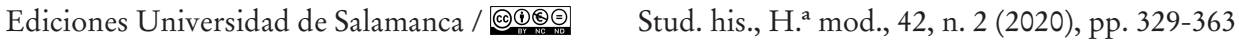


MANUEL ALEJANDRO CASTELLANO GARCÍA

GRAN BRETAÑA Y LA CUESTIÓN CATALANA: LA NEGOCIACIÓN HISPANOBRITÁNICA DURANTE EL FINAL DE LA GUERRA DE SUCESIÓN ESPAÑOLA

de la que hubiera deseado al haber decidido entre franceses y británicos el grueso de las cuestiones referentes a su monarquía, su actitud mostró un mayor grado de independencia respecto a Luis XIV de la que en principio se esperaba. Como ya hizo al elegir el trono español frente a los deseos de su abuelo (Bély, 2007: 465-471), dentro del límite de acción en que podía desenvolverse mostró fuerte resistencia en su afán por aparecer como un monarca por derecho propio, aprovechando el margen de maniobra que le daba el interés británico por concluir la contienda y confirmar las ventajas obtenidas para mantenerse firme ante ciertas cuestiones y lograr algunas victorias en la negociación. Es en esa esfera en la que -igual que con la soberanía para la princesa de los Ursinos, aunque con mejor fortuna para los intereses de Felipe V-, se encuadra la inflexibilidad que, a despecho de las enormes presiones recibidas, mantuvo en la cuestión catalana.

Pero que la conservación de las leyes catalanas bien pudiera considerarse un tema de menor entidad entre los múltiples puntos a acordar en las paces no implica que fuese una cuestión residual. Que se convirtiese en punto clave de la negociación hispano-británica, su solución parcial en Utrecht requiriese presiones y esfuerzos conjuntos de franceses y británicos y se convirtiese en un tema recurrente hasta la paz de Viena de 1725 da buena prueba de que acabó sobrepasando la relevancia que en principio se le había supuesto. Que además afectase al desarrollo de la vida política de Gran Bretaña llegando a ser uno de los temas más debatidos en el Parlamento durante 1713 y 1714 nos confirma que devino en mucho más que una mera cuestión interna de la monarquía hispánica, siendo en buena medida la irreductible actitud de Felipe $\mathrm{V}$ lo que la convirtió en un inesperado engorro para Gran Bretaña.

Dicha actitud entronca más con aquellas actitudes maximalistas iniciales que con el monarca que, más adelante, dirigió sus ojos a conservar lo posible en Italia como cabeza de puente para intentar recuperar lo perdido en la Europa post-Utrecht. Lo cierto es que sabiendo que era improbable que se llegase a romper el acuerdo de paz por esta cuestión mantuvo fija su postura y acabó forzando a los británicos a plegarse a sacrificar a sus aliados catalanes. $\mathrm{Y}$ aunque ciertamente la tendencia uniformizadora borbónica presuponía una actuación encaminada a eliminar las leyes catalanas, el empecinamiento que mostró en dar un escarmiento ejemplar, incluso contra los consejos de Luis XIV, o su furia cuando Lexington insistió en conseguir la conservación de las leyes catalanas parecen apuntar más a una cuestión cuasi-personal rozando en ocasiones la venganza aunque para ello debiese dejar de lado todo pragmatismo político y estratégico.

Cabe pensar si la obcecación en esa pequeña victoria en el conjunto de una negociación en la que tanto perdía no le servía en cierto modo para evitar iniciar la andadura de una nueva dinastía con una derrota en todos los frentes, pudiendo consolarse no solo con mantener la integridad de sus territorios peninsulares -y de las Indias- sino también con haber conseguido imponer su firme autoridad frente

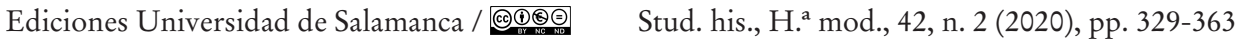


MANUEL ALEJANDRO CASTELLANO GARCÍA

GRAN BRETAÑA Y LA CUESTIÓN CATALANA: LA NEGOCIACIÓN HISPANOBRITÁNICA DURANTE EL FINAL DE LA GUERRA DE SUCESIÓN ESPAÑOLA

a todos aquellos súbditos que en esos territorios habían tratado de situarse por encima de su voluntad.

\section{BIBLIOGRAFÍA}

(1714). The case of the catalans consider'd. Londres: J. Baker. Londres.

(1715). A report from the Committee of Secrecy, appointed by order of the House of Commons to examine several books and papers laid before the House, relating to the late negotiations of Peace and Commerce, reported on the Nine of June, 1715. Londres: Thomas Hume.

Albareda Salvadó, J. (2000). La guerra de successió i l'onze de setembre. Barcelona: Empuries. Albareda Salvadó, J. (2002). Felipe V y el triunfo del absolutismo. Cataluña en un conflicto europeo (1700-1714). Barcelona: Generalitat de Catalunya, Entitat Autònoma del Diari Oficial i de Publicacions.

Albareda Salvadó, J. (2005). El «Cas dels catalans». la conducta dels aliats arran de la guerra de successió, 1705-1742. Barcelona: Fundació Noguera.

Albareda Salvadó, J. (2010). La guerra de Sucesión de España (1700-1714). Barcelona: Crítica. Albareda Salvadó, J. (2013). Felipe y la negociación de los tratados de Utrecht: bajo los dictados del mejor abuelo del mundo. 1713: la monarquía de España y los tratados de Utrecht, Cuadernos de Historia Moderna. Anejos, 12, 31-60.

Albareda Salvadó, J. (2015). Los tratados de Utrecht-Rastatt y España: ceder lo mínimo para conservar lo principal. En J. Albareda (ed.), El declive de la monarquía y del imperio español: los tratados de Utrecht, (1713-1714) (pp. 65-122). Barcelona: Crítica.

Albareda Salvadó, J. (2018). Une principauté pour la princesse des Ursins: difficultés et échec. En G. Hanotin y D. Pico (dirs.), Le lion et les lys : Espagne et France au temps de Philippe V (pp. 189-206). Burdeos: Presses Universitaires de Bourdeux.

Albertí, S. (1964). L’onze de setembre. Barcelona: Albertí Editor.

Baudrillart, A. (1890). Philippe V et la cour de France d'après des documents inédits tirés des archives espagnoles de Simancas et d'Alcala de Hénarès, et des Archives du Ministère des affaires étrangères à Paris, Vol. I. Paris: Librairie de Fermin-Didot.

Bély, L. (1990). Espions et ambassadeurs au temps de Louis XIV. París: Fayard.

Bély, L. (2007). L'Art de la paix en Europe: naissance de la diplomatie moderne, XVIeXVIIIe siècle. Paris: Presses universitaires de France.

Bély, L. (2015). Ombres et lumieres dans l'Europe de la paix d'Utrecht (1713-1714). En C. Mollfulleda y N. Sallés (eds.). Els Tractats d'Utrecht clarors i foscors de la pau, la resistència dels catalans: 9-12 de abril, actes del congrés (pp. 19-25). Barcelona: Museu d'Historia de Catalunya.

Bluche, F. (1998). Le Journal secret du Louis XIV. París : Ed. Du Rocher.

Cases Ibañez, A. (2013). La participació portuguesa al front català durant la guerra de Successió (1707-1713). En J. Dantí, X. Gil e I. Mauro (coords.), Actes del VIII congrés d'Història Moderna de Catalunya: "Catalunya, entre la guerra i la pau, 1713, 1813».

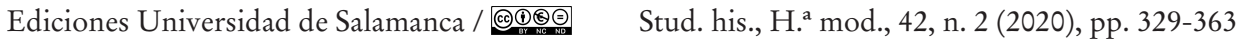


MANUEL ALEJANDRO CASTELLANO GARCÍA GRAN BRETAÑA Y LA CUESTIÓN CATALANA: LA NEGOCIACIÓN HISPANOBRITÁNICA DURANTE EL FINAL DE LA GUERRA DE SUCESIÓN ESPAÑOLA

Barcelona, 17-20 decembre de 2013: comunicacions (I, pp. 24-49). Barcelona: Universitat de Barcelona.

Castellano García, M. (2016). François Gaultier, un artisan de la paix d'Utrecht, 1711-1713. Revue d'Histoire Diplomatique, 132(3), 257-275.

Castellví i Obando, F. (1997-2002). Narraciones históricas. En J. M. Mundet y J. Alsina (eds.), Vol. III, Madrid: Fundación Francisco Elías de Tejada y Erasmo Pércopo.

Cobbet, W. (1811). The Parliamentary History of England. From the Normand conquest, in 1066, to the year 1803, Vol. VII. Londres: T. C. Hansard.

Courcy, marqués de. (1889). Renonciation des Bourbons d'Espagne au trone de France. Paris: Plon Nourrit.

Coward, B. (2003). The Stuart Age: England 1603-1714. Londres: Longman.

Désos, C. (2009) Les français de Philippe V. Un modèle nouveau pour gouverner l'Espagne (1700-1724). Estrasburgo: Presses Universitaires de Strasbourg.

Fernández Durán, R. (2011). La corona española y el tráfico de negros: del monopolio al libre comercio. Madrid: Ecobook.

García Cárcel, R. (1998). La opinión catalana sobre Francia en la primera mitad del siglo XVIII. Pedralbes: Revista d'Història moderna, 18(2), 421-437.

García i Espuche, A. (2014). Una societat assetjada. Barcelona 1713-1714. Barcelona: Empuries.

Gregg, E. (2001). Queen Anne. New Haven \& Londres: Yale University Press.

Guerrero Villar, J. (2008). El tratado de paz con Inglaterra de 1713. Orígenes y culminación del desmembramiento de la monarquía española (Tesis doctoral). Universidad Autónoma de Madrid.

Guillamón Álvarez, F. J y Muñoz Rodríguez, J. D. (eds.). (2008). Educando al Príncipe: correspondencia privada de Luis XIV a Felipe V durante la guerra de Sucesión. Rosario: Prohistoria.

Henderson, N. (2002). Prince Eugene of Savoy: a biography. Londres: Phoenix.

Hill, B. W. (1988). Robert Harley, Speaker, Secretary of State and Premier Minister. New Haven \& Londres: Yale University Press.

Hoppit, J. (2000). A land of liberty? England 1689-1727. Oxford: Clarendon Press.

Horowski, L. (2018). Subjects into sovereigns: The outsiders' pursuit of sovereignity and the war of the Spanish sucession. En M. Pohlig y M. Schaich (dirs.), The war of the Spanish Succession: new perspectives (pp. 101-130). Oxford: Oxford University Press.

Horn, D. B. (1961). The British diplomatic service, 1698-1789. Oxford: Clarendon Press.

León Sanz, V. (2003). Carlos VI, el emperador que no pudo ser rey de España. Madrid: Santillana Ediciones generales.

León Sanz, V. (2013). De La Haya a Utrecht. Las negociaciones de paz en la Corte de Barcelona (1709-1714). En J. Dantí, X. Gil e I. Mauro (coords.), Actes del VIII congrés d'Història Moderna de Catalunya: "Catalunya, entre la guerra i la pau, 1713, 1813»: Barcelona, 17-20 decembre de 2013: comunicacions (I, pp. 93-123). Barcelona: Universitat de Barcelona.

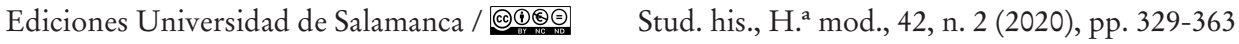


MANUEL ALEJANDRO CASTELLANO GARCÍA

GRAN BRETAÑA Y LA CUESTIÓN CATALANA: LA NEGOCIACIÓN HISPANOBRITÁNICA

DURANTE EL FINAL DE LA GUERRA DE SUCESIÓN ESPAÑOLA

León Sanz, V. (2015). Al servicio de Carlos VI. El partido español en la corte imperial. En J. Albareda (ed.), El declive de la monarquía y del imperio español: los tratados de Utrecht, (1713-1714) (pp. 225-275). Barcelona: Crítica.

Martín Marcos, D. (2014). Portugal entre Methuen y Utrecht. En M. Torres Arce y S. Truchuelo García (eds.), Europa en torno a Utrecht (pp. 65-88). Santander: Universidad de Cantabria.

Muñoz González, A. y Catà i Tur, J. (2009). La traïció anglesa. Comerç colonial i destrucció de la sobirania catalana (1706-1715). Barcelona: Llibres de l'Índex.

Parke, G. (ed.). (1798). Letters and correspondance, public and private, of the Right Honourable Henry St. John, lord viscount Bolingbroke, during the time he was secretary of state to Queen Anne, with state papers, explanatory notes and a translation of foreign letters, Vols. II-III-IV. Londres: G. G. \& J. Robinson.

Sanpere i Miquel, S. (1905). Fin de la nación catalana. Barcelona: Tipografia l'Avenç. [Ed. Facsimil (2001). Barcelona: Base].

Soldevila, F. (1995). Anglaterra i Catalunya. Les relacions anglo-catalanes durant la guerra de Successió. Manuscrits: revista d'història moderna, 13, 13-30.

Storrs, C. (2013). How wars end: Lord Lexington's mission to Madrid: 1712-1713. 1713: la monarquía de España y los tratados de Utrecht, Cuadernos de Historia Moderna. Anejos, 12, 77-99.

Torcy, marqués de. (1757). Memoires du monsieur du Torcy : pour servir a la l'bistoire des negociations. Depuis le Traité de Ryswyck jusqu'à la paix d'Utrecht, Vol. III. Londres: Chez Nurse \& Vaillant.

Torras i Ribé, J. M. (2000). La rereguarda catalana entre la darrera ofensiva aliada i el capgirament internacional. Manuscrits, 18, 63-91.

Torras i Ribé, J. M. (2013). Antecedentes y consecuencias de la negociación de Utrecht en Cataluña (1711-1713). 1713: la monarquía de España y los tratados de Utrecht, Cuadernos de Historia Moderna. Anejos, 12, 133-152.

Torras i Ribé, J. M. (2015). El principi de la fi de la Guerra de Successió a Catalunya: de les negociacions d'Utrecht al conveni de l'Hospitalet (1711-1713). En C. Mollfulleda y N. Sallés (eds.), Els Tractats d'Utrecht clarors i foscors de la pau, la resistència dels catalans: 9-12 de abril, actes del congrés (pp, 297-306). Barcelona: Museu d'Historia de Catalunya.

Ediciones Universidad de Salamanca / 요 Stud. his., H. ${ }^{a}$ mod., 42, n. 2 (2020), pp. 329-363 
